\title{
Regulator of calcineurin 1 mediates pathological vascular wall remodeling
}

\author{
Vanesa Esteban, ${ }^{1}$ Nerea Méndez-Barbero, ${ }^{1}$ Luis Jesús Jiménez-Borreguero, ${ }^{2}$ \\ Mercè Roqué, ${ }^{3}$ Laura Novensá, ${ }^{3}$ Ana Belén García-Redondo, ${ }^{4}$ \\ Mercedes Salaices, ${ }^{4}$ Luis Vila, ${ }^{5}$ María L. Arbonés, ${ }^{6}$ Miguel R. Campanero, ${ }^{7}$ \\ and Juan Miguel Redondo ${ }^{1}$
'Department of Vascular Biology and Inflammation, Centro Nacional de Investigaciones Cardiovasculares (CNIC), E-28029 Madrid, Spain
2Department of Atherotrombosis and Imaging, CNIC and Hospital de la Princesa, E-28029 Madrid, Spain
${ }^{3}$ Department of Cardiology, Institut del Tòrax, Institut d'Investigacions Biomèdiques Agustí Pi Sunyer, Hospital Clínic, 08036 Barcelona, Spain
${ }^{4}$ Department of Pharmacology, Facultad de Medicina, Universidad Autónoma de Madrid, E-28029 Madrid, Spain
${ }^{5}$ Laboratory of Angiology, Vascular Biology and Inflammation, Institute of Biomedical Research (II-B Sant Pau), E-08025 Barcelona, Spain
${ }^{6}$ Instituto de Biología Molecular de Barcelona, CSIC, Parc Cientific de Barcelona, and Centro de Investigaciones Biomédicas en Red de Enfermedades Raras (CIBERER), E-08028, Barcelona, Spain \\ ${ }^{7}$ Department of Cancer Biology, Instituto de Investigaciones Biomedicas Alberto Sols, CSIC-UAM, E-28029 Madrid, Spain
}

\begin{abstract}
Artery wall remodeling, a major feature of diseases such as hypertension, restenosis, atherosclerosis, and aneurysm, involves changes in the tunica media mass that reduce or increase the vessel lumen. The identification of molecules involved in vessel remodeling could aid the development of improved treatments for these pathologies. Angiotensin II (Angll) is a key effector of aortic wall remodeling that contributes to aneurysm formation and restenosis through incompletely defined signaling pathways. We show that Angll induces vascular smooth muscle cell (VSMC) migration and vessel remodeling in mouse models of restenosis and aneurysm. These effects were prevented by pharmacological inhibition of calcineurin (CN) or lentiviral delivery of $\mathrm{CN}$-inhibitory peptides. Whole-genome analysis revealed $>1,500$ Angll-regulated genes in VSMCs, with just 11 of them requiring $\mathrm{CN}$ activation. Of these, the most sensitive to $\mathrm{CN}$ activation was regulator of $\mathrm{CN} 1$ (Rcan 1). Rcan 1 was strongly activated by Angll in vitro and in vivo and was required for Angll-induced VSMC migration. Remarkably, Rcan 1-I- mice were resistant to Angll-induced aneurysm and restenosis. Our results indicate that aneurysm formation and restenosis share mechanistic elements and identify Rcan 1 as a potential therapeutic target for prevention of aneurysm and restenosis progression.
\end{abstract}

\section{CORRESPONDENCE}

Miguel R. Campanero:

mcampanero@iib.uam.es

$\mathrm{OR}$

Juan Miguel Redondo:

jmredondo@cnic.es

Abbreviations used: AAA, abdominal aortic aneurysm; AngII, angiotensin II; CN, calcineurin; CsA, cyclosporin A; RCAN, regulator of $\mathrm{CN}$; SMA, smooth muscle $\alpha$-actin; VSMC, vascular smooth muscle cell.
The arterial wall is composed of three independent layers (intima, media, and adventitia) that display a variety of physiological properties. The intima is a monolayer of interconnected endothelial cells attached to a thin extracellular matrix. The media, delimited by the hydrophobic internal and external elastic laminas, is the main structural component of the arterial wall and is mostly composed by vascular smooth muscle cells (VSMCs). A network of connective tissue, nerve endings, fibroblasts, and a few quiescent resident leukocytes compose the adventitia. The medial VSMCs help to maintain

V. Esteban and N. Méndez-Barbero contributed equally to this paper. vascular integrity. Under physiological conditions, VSMCs are quiescent, contractile, and nonmigratory, and display a differentiated phenotype. Pathological vascular wall remodeling involves structural and functional modifications that destabilize the ordered multilayered structure of the wall and change the mass of the tunica media (Heeneman et al., 2007). Remodeling occurs in response to various stimuli, including blood pressure changes, inflammatory responses, altered extracellular matrix composition, and Noncommercial-Share Alike-No Mirror Sites license for the first six months after the publication date (see http://www.rupress.org/terms). After six months it is available under a Creative Commons License (Attribution-Noncommercial-Share Alike 3.0 Unported license, as described at http://creativecommons.org/licenses/ by-nc-sa/3.0/) 
vessel injury. These stimuli activate resident medial VSMCs, among other cells, which contribute to vascular remodeling through numerous processes, including cell migration (Berk, 2001). VSMC migration is critical for lesion development and progression in several vascular pathologies. VSMCs migrate toward specific chemoattractants released by monocytes/macrophages, platelets, endothelial cells, or other VSMCs in the damaged vessel (Goetze et al., 1999).

Vascular remodeling is a central feature of diseases such as hypertension, restenosis, atherosclerosis, and aneurysm (Heeneman et al., 2007). For example, percutaneous balloon angioplasty, commonly used to treat ischemic heart disease and peripheral artery stenosis (obstruction), causes severe vascular wall remodeling, resulting in restenosis. Vascular wall remodeling is also observed in the aneurismal degeneration of the abdominal aortic and iliac arteries (referred to as abdominal aortic aneurysm [AAA]; Heeneman et al., 2007; Forte et al., 2010). Intimal hyperplasia formation and restenosis can be controlled by the use of drug-eluting stents (Iakovou et al., 2005) and pharmacological control of atherosclerotic risk factors can slow AAA growth in some cases (Chaikof et al., 2009). However, there is as yet no definitive treatment to prevent restenosis or the progression of small aneurysms. The identification of molecules involved in vessel remodeling could therefore aid the development of treatments for these pathologies.

Angiotensin II (AngII), the key product of the reninangiotensin system, is one of the most important factors influencing vascular remodeling (Berk, 2001), contributing to altered vascular tone, VSMC dysfunction, and structural remodeling in response to vascular damage (Touyz, 2005). AngII induces VSMC migration (Greene et al., 2001) and contributes to aneurysm formation and restenosis in animal models and in humans (Daugherty et al., 2000; Heeneman et al., 2007; Weintraub, 2009). Two major AngII cell surface receptor subtypes have been cloned and characterized, AT1R and AT2R (Benigni et al., 2010). Both receptors play a role in regulating VSMC function but are thought to oppose each other (Benigni et al., 2010).

Despite the importance of AngII and VSMC migration and vascular remodeling, little is known about the signaling pathways that regulate these processes. One of the downstream effectors of AngII is the ubiquitously expressed serine/ threonine protein phosphatase CN (Crabtree and Olson, 2002; Suzuki et al., 2002; Martínez-Martínez and Redondo, 2004), whose primary and most thoroughly characterized substrates are members of the nuclear factor of activated T cells family (NFATc1, NFATc2, NFATc3, and NFATc4). Dephosphorylation of NFATs triggers their rapid translocation to the nucleus where they become transcriptionally active (Hogan et al., 2003). The CN-NFAT axis is implicated in several pathophysiological processes, including vascular and neural development, diabetes, and cardiac hypertrophy (Molkentin et al., 1998; Graef et al., 2001, 2003; Heit et al., 2006). CN is inhibited by cyclosporin A (CsA; Liu et al., 1991; Cardenas et al., 1995), and NFAT activation by CN can also be inhibited by overexpressing peptides that block the interaction of $\mathrm{CN}$ with the two docking sites present in the NFAT regulatory domain, one at the N-terminal (VIVIT peptide) and the other at the C-terminal (LxVP peptide; Aramburu et al., 1999; Liu et al., 1999; Martínez-Martínez et al., 2006). A family of endogenous CN modulators, called regulators of CN (RCANs; previously known as DSCR/ $\mathrm{MCIP} /$ calcipressin/Adapt78 in mammals), has recently been identified (Davies et al., 2007). RCAN1, identified through its association with Down syndrome (Fuentes et al., 1997), is implicated in several physiological and pathological processes, including tumor growth and angiogenesis, sepsis, cardiac hypertrophy, mast cell function, and synaptic plasticity and memory (Rothermel et al., 2001; Ryeom et al., 2003, 2008; Vega et al., 2003; Hoeffer et al., 2007; Baek et al., 2009; Minami et al., 2009; Yang et al., 2009).

To date, neither CN-NFAT signaling nor RCAN1 have been linked to AngII-elicited vessel remodeling. Although NFAT transcription factors are implicated in AngII signaling in VSMCs, published studies provide conflicting data on which NFATs mediate AngII signals in these cells (Suzuki et al., 2002; Yellaturu et al., 2002; Liu et al., 2005). Indeed, little is known about the signaling pathways regulating vascular wall remodeling. In this paper, we show for the first time that CN and RCAN1 mediate AngII-induced VSMC migration, and, using mouse models of restenosis and aneurysm, demonstrate that AngII induces pathological artery wall remodeling via $\mathrm{CN}$ and RCAN1.

\section{RESULTS \\ The CN-NFAT pathway is activated by Angll in vivo and mediates Angll-induced migration of VSMCs}

To address the role of the CN-NFAT pathway in AngIIinduced signaling in VSMCs in vivo, we used minipump infusion to treat mice with AngII and/or the CN inhibitor CsA. The presence of activated NFAT factors in the nuclei of cells of the aortic wall was then analyzed by in situ southwestern histochemistry on aortic sections. We found that AngII induced sustained in vivo activation of NFAT factors in aortic VSMCs, endothelial cells, and adventitial cells (Fig. 1, A and B; and Fig. S1). NFAT staining was similar to that of SP1 (Fig. $1 \mathrm{C}$ ), which is used as a control for nuclear staining pattern. NFAT activation was prevented by CsA and blockers of AngII type 1 receptor $\left(A_{1} R\right)$ but not AngII type 2 receptor $\left(\mathrm{AT}_{2} \mathrm{R}\right.$; Fig. $\left.1 \mathrm{~A}\right)$.

To determine which NFAT family members mediate AngII signals in VSMCs, we analyzed their expression and dephosphorylation status (an index of activation). NFATc1, NFATc3, and NFATc4, but not NFATc2, were detected in untreated VSMCs and were readily dephosphorylated by AngII in a CsA-sensitive manner (Fig. 1 D).

We next investigated the potential role of CN in AngIIinduced VSMC migration. AngII increased VSMC motility in Transwell assays, and this was inhibited by pretreatment with CsA (Fig. 2, A and B). We previously showed that infection with lentivirus encoding GFP fused to LxVP or VIVIT peptides 
A

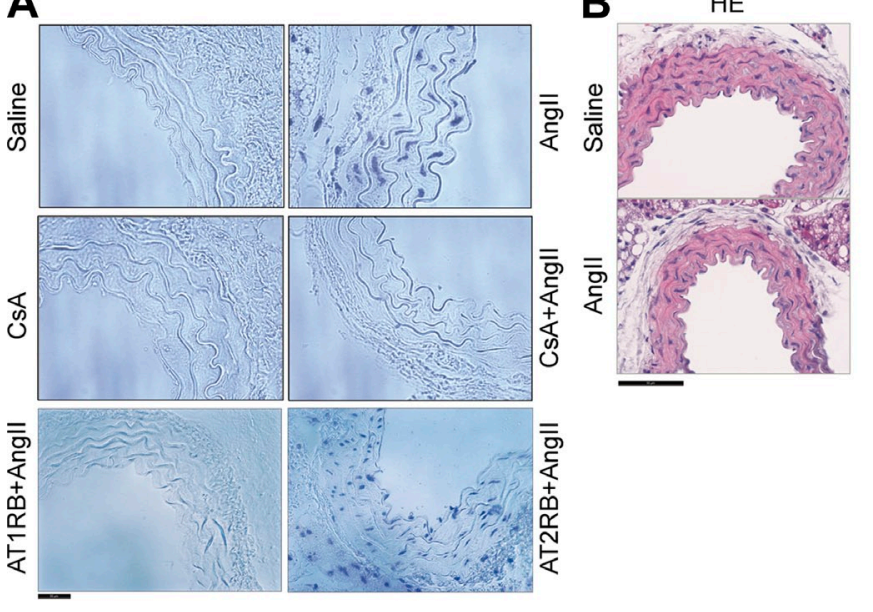

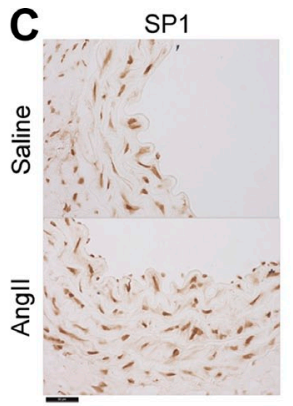

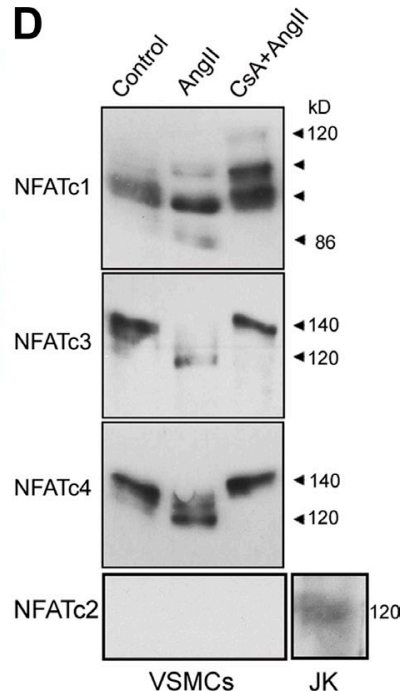

Figure 1. Angll activates the CN-NFAT pathway in VSMCs in vivo. (A-C) Mice were inoculated with $5 \mathrm{mg} / \mathrm{kg} / \mathrm{d} \mathrm{CsA}, 10 \mathrm{mg} / \mathrm{kg} / \mathrm{d}$ of the Angll type 1 receptor $\left(\mathrm{AT}_{1}\right)$ blocker losartan, or $30 \mathrm{mg} / \mathrm{kg} / \mathrm{d}$ of the Angll type 2 receptor $\left(\mathrm{AT}_{2}\right)$ blocker PD123319 by subcutaneous osmotic minipump infusion for $24 \mathrm{~h}$ before similar administration of $1 \mu \mathrm{g} / \mathrm{kg} / \mathrm{min}$ Angll for $1 \mathrm{~h}$. Aortic sections from these mice were analyzed by Southwestern histochemistry with NFAT probe (A), hematoxylin-eosin (HE) staining (B), and Sp1 immunohistochemistry (C). Bars, $50 \mu \mathrm{m}$. (D) NFAT immunoblot in extracts from VSMCs stimulated with $1 \mu \mathrm{M}$ Angll for $1 \mathrm{~h}$ after pretreatment as indicated $(1 \mathrm{~h})$ with $200 \mathrm{ng} / \mathrm{ml}$ CsA. Arrowheads indicate NFAT proteins with different degrees of phosphorylation. NFATc2 was tested in parallel protein extracts of Jurkat cells (JK). Representative experiments are shown of four to six performed.

prevents NFAT activation (Martínez-Martínez et al., 2006; Rodríguez et al., 2009). Expression of GFP-LxVP or GFPVIVIT in VSMCs (Fig. S2 A) abolished the VSMC migratory response to AngII (Fig. $2 \mathrm{C}$ and Fig. S2 B). In contrast, GFP-LxVPmut, encoding a mutated LxVP peptide, had no effect (Fig. $2 \mathrm{C}$ and Fig. S2 B).

\section{CN is implicated in Angll-induced arterial damage}

To assess the involvement of AngII signaling in pathological vascular remodeling, we first used a mouse model in which femoral artery injury is induced by passage of an angioplasty guidewire, mimicking the damage caused by angioplasty in humans (Roque et al., 2000). Guidewire injury promoted neointima formation (Fig. 3). AngII infusion increased this intimal thickening without disrupting elastic integrity (Fig. 3 A), which was reflected in a sharply increased intima/media
(I/M) ratio (Fig. $3 \mathrm{C}$ ) and a decrease in lumen area (Fig. 3 B). AngII-promoted inward growth was blocked by pretreatment with CsA, which also protected against basal injury-induced neointima formation, reducing the $\mathrm{I} / \mathrm{M}$ ratio and the percent of stenosis almost to basal (noninjured) levels (Fig. 3).

Extensive remodeling of the artery wall is a hallmark of aneurysm formation and progression (Heeneman et al., 2007), a process promoted by AngII in animal models and humans (Weintraub, 2009). To investigate the mechanisms underlying AngII-induced aneurysm, we used the apolipoprotein E-deficient $\left(A p o e^{-/-}\right)$mouse model. As previously described (Daugherty et al., 2000; Daugherty and Cassis, 2004), AngII promoted the formation of AAA in $A p o e^{-/-}$mice (Fig. 4). This effect was strongly reduced by pretreatment with CsA (Fig. 4); whereas 79\% of Apoe ${ }^{-/-}$mice treated with AngII alone developed AAA, only $11 \%$ of mice pretreated with
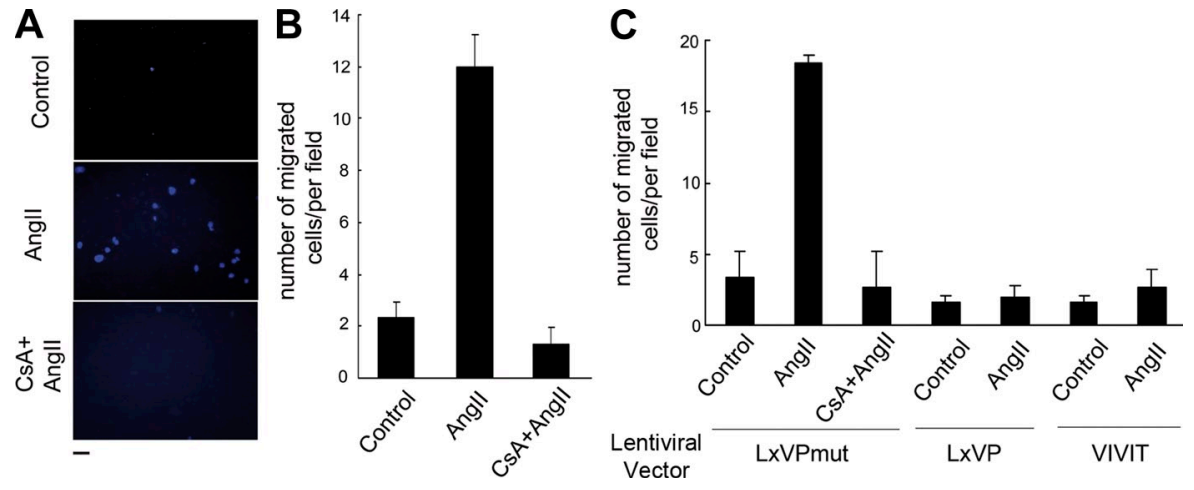

Figure 2. CN mediates Angll-induced VSMC migration. ( $A$ and $B$ ) VSMCs were seeded on the upper surface of the polycarbonate membranes of chemotaxis (Transwell) chambers containing no stimulus, $1 \mu \mathrm{M}$ Angll, or $1 \mu \mathrm{M}$ Angll plus $200 \mathrm{ng} / \mathrm{ml}$ CsA in the lower chamber. After $4 \mathrm{~h}$, nonmigrating cells were removed from the upper filter surfaces and the filter was stained with Hoechst. (A) Representative images of the lower filter surface. Bar, $50 \mu \mathrm{m}$. (B) Quantification of migrated VSMCs in 10 fields per condition in a representative transwell experiment of six to seven performed (means \pm SEM). (C) VSMCS

infected with lentiviruses expressing GFP-tagged LxVP, LxVPmutant, or VIVIT peptides and treated as indicated in A and B. Quantification is shown of migrated VSMCs in 10 fields per condition in a representative transwell experiment of six to seven performed (means \pm SEM). 
A Non-injured

Injured
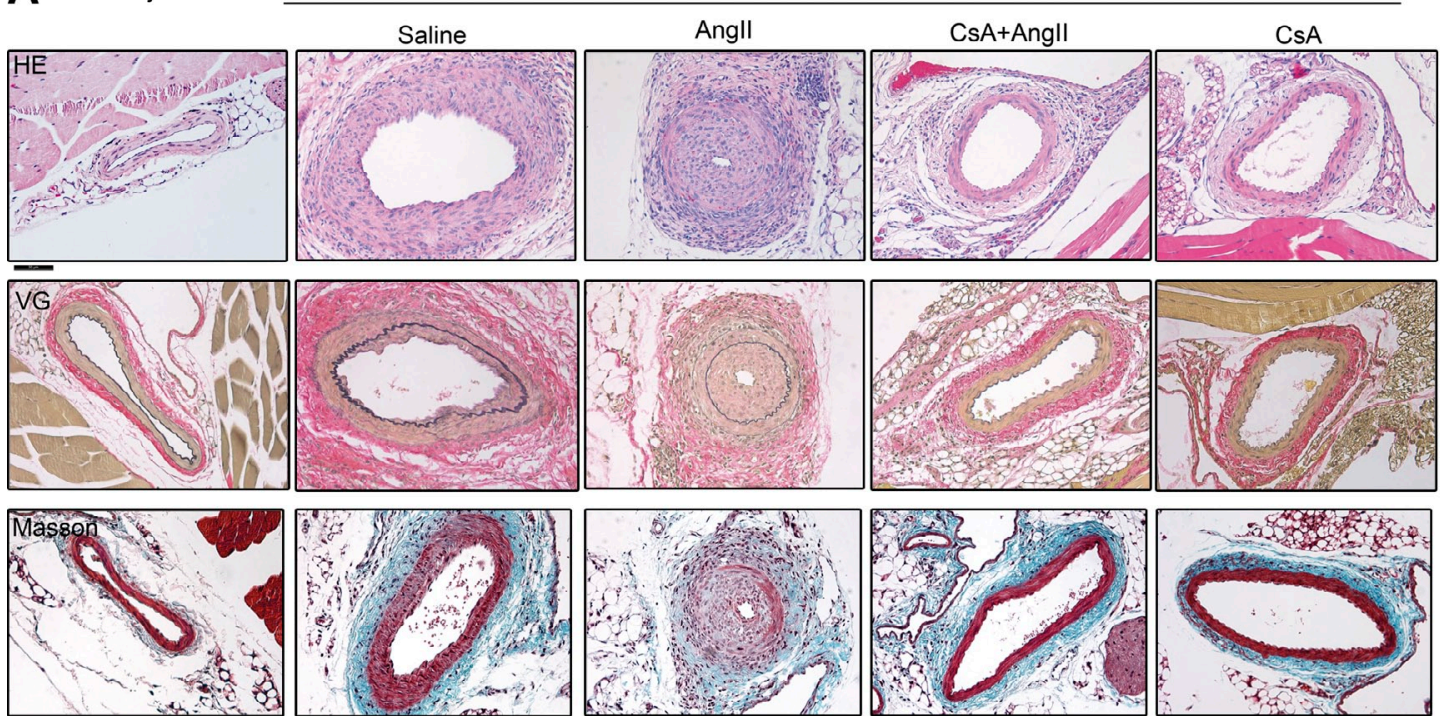

B

\begin{tabular}{|c|c|c|c|c|c|}
\hline Treatment & Adventitia area & Media area & Intimal area & Lumen area & $\%$ Stenosis \\
\hline Saline & $119,469 \pm 38,153$ & $53,425 \pm 11,141$ & $21,872 \pm 8,152$ & $43,469 \pm 19,087$ & $36.62 \pm 17.11$ \\
\hline Ang II & $122,393 \pm 13,211$ & $45,579 \pm 7,260$ & $87,938 \pm 29,246$ & $24,512 \pm 11,499$ & $68.45 \pm 11.40$ \\
\hline CsA +Ang II & $53,357 \pm 8,239$ & $35,883 \pm 5,026$ & $8,396 \pm 5,134$ & $40,246 \pm 7,101$ & $11.31 \pm 6.93$ \\
\hline CsA & $59,103 \pm 17,122$ & $38,374 \pm 9,538$ & $407 \pm 482$ & $48,507 \pm 21,475$ & $0.73 \pm 0.86$ \\
\hline \multicolumn{7}{|l|}{} \\
\hline Non Injured & $16,942 \pm 2,594$ & $19,505 \pm 1,232$ & 0 & $12,282 \pm 2,169$ & 0 \\
\hline
\end{tabular}
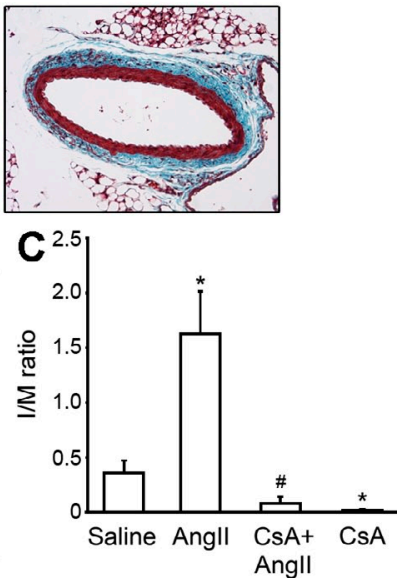

Figure 3. CsA inhibits Angll-induced neointimal formation in a model of femoral artery injury. The left femoral artery was wire injured and Angll was administrated by subcutaneous minipump infusion during $14 \mathrm{~d}$. CsA administration commenced $24 \mathrm{~h}$ before treatment with Angll and continued throughout the Angll infusion period. (A) Representative images of left femoral artery cross sections stained with hematoxylin-eosin (HE), Van Gieson (VG), and Masson's trichrome (Masson). Bar, $50 \mu \mathrm{m}$. (B) Summary of morphometric data of the different treatment groups. Area data are shown in micrometers squared. Because the endothelial monolayer appeared as a line in the noninjured arteries, its area was considered to be 0 , and the mean I/M ratio and percentage of stenosis were also 0 . (C) Quantification of the ratio of the thickness of intima and media (I/M ratio) in the injured conditions shown in $\mathrm{A}$. Data are means \pm SEM. Numbers of mice per group were 7 saline, 13 Angll, 7 CsA+Angll, 5 CsA, and 10 noninjured. ${ }^{*}, P<0.05$ versus control;

$\#, P<0.05$ versus Angll. Results in $A-C$ were pooled data from two independent experiments.

CsA developed the condition. CsA prevented AngII-induced changes in overall abdominal aorta morphology (Fig. 4 A), blocked the increase in aorta diameter (Fig. 4, B and C) and collagen deposition (Fig. 4 D), and prevented destabilization of the ordered multilayered artery wall structure (Fig. 4 D). Treatment with CsA alone did not significantly modify overall aorta morphology or maximal diameter (Fig. 4, A-C). Remarkably, numerous adventitial cells were positive for smooth muscle $\alpha$-actin (SMA) in aneurysm sections from AngIIinfused mice (Fig. 4 E).

To confirm the involvement of $\mathrm{CN}$ in AngII-induced AAA, we inoculated Apoe ${ }^{-1-}$ mice with lentivirus encoding LxVP or LxVPmutant before AngII infusion. This systemic administration yielded efficient transduction of VSMCs in vivo (Fig. $5 \mathrm{~A}$ ). LxVP, but not LxVPmutant, completely prevented AngII-induced AAA (Fig. 5 B). Active NFAT was abundant in aneurysm sections of AngII-treated mice but was not detected in sections from CsA-pretreated mice or from animals infected with LxVP lentiviruses, thus establishing a clear correlation between activation of the CN-NFAT pathway by AngII and subsequent arterial damage (Fig. 5 C).

\section{Rcan1-4 is required for Angll-induced migration of VSMCs}

To investigate the mechanism by which CN mediates AngIIinduced vascular damage, we screened mouse aortic VSMCs for expression of AngII-regulated genes sensitive to CsA. Analysis of mouse whole-genome arrays with gene expression dynamics inspector (Eichler et al., 2003) revealed that AngII altered the expression of many genes in mouse aortic VSMCs, whereas CsA barely affected gene expression and did not grossly alter the transcriptome of AngII-treated cells (unpublished data). Just 11 of $>1,500$ AngII-regulated genes were significantly affected by CsA treatment (Fig. 6 A), arguing strongly for a specific action of $\mathrm{CN}$ signaling in the AngII response. Of these genes, only Rcan 1 was inhibited by $>70 \%$ and was thus identified as a candidate mediator of AngII signaling in VSMCs. 
A
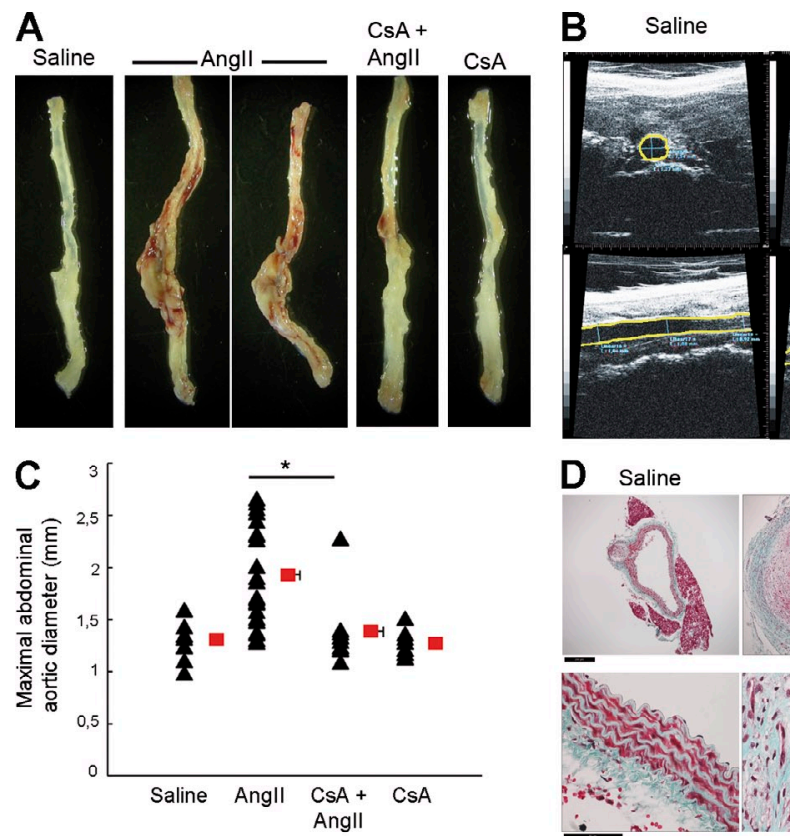

D Saline
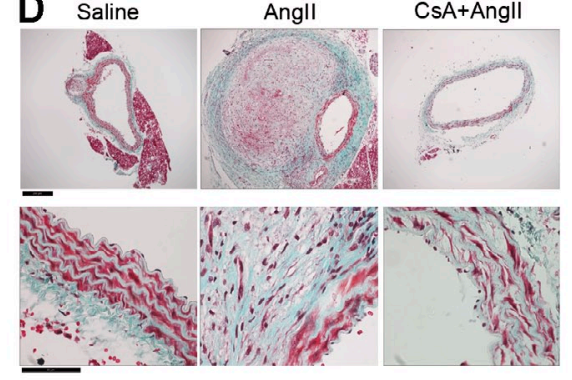

Angll
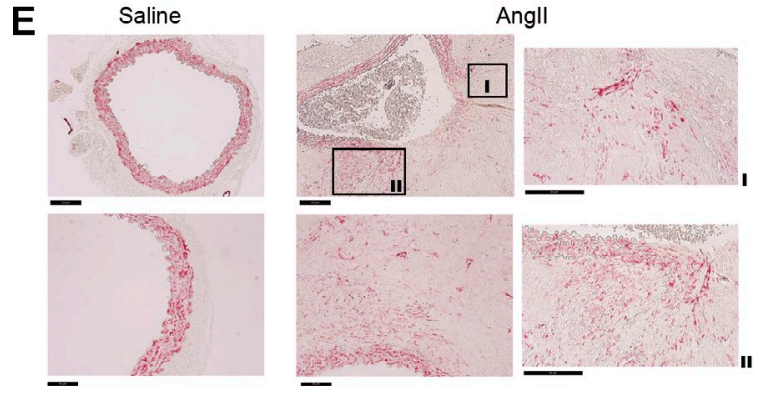

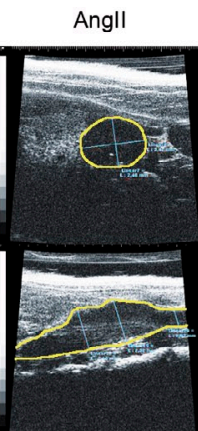

Angll

CsA+Angll

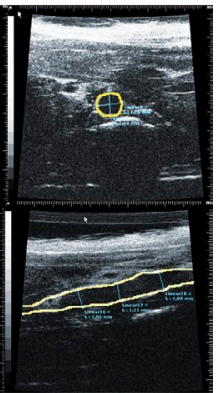

CsA+Angll

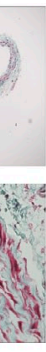

Figure 4. CsA inhibits development of Angll-induced AAA. Apoe ${ }^{-1-}$ mice were minipump infused with $5 \mathrm{mg} / \mathrm{kg} / \mathrm{d} \mathrm{Cs}_{1}, 1 \mathrm{~d}$ before commencing similar administration with saline or $1 \mu \mathrm{g} / \mathrm{kg} / \mathrm{min}$ Angll for $28 \mathrm{~d}$. (A) Representative abdominal aortas of Apoe ${ }^{-1-}$ mice treated as indicated. (B) Representative high-frequency ultrasound (US) images of abdominal aortas. Transverse (top) and longitudinal (bottom) images were taken at the level of the suprarenal aorta. Yellow lines mark the lumen boundary. (C) Maximum suprarenal abdominal aortic diameter (in millimeters) measured from transverse US images. Triangles and squares represent individual mice and means \pm SEM, respectively. Numbers of mice per group were 9 saline, 24 Angll, 9 CsA+Angll, and 7 CsA. ${ }^{*}, \mathrm{P}<0.05$ versus Angll. (D) Representative Masson's trichrome staining of suprarenal abdominal aorta cross sections. Bars: $200 \mu \mathrm{m}$ (top); $50 \mu \mathrm{m}$ (bottom). (E) Representative immunohistochemical staining for SMA in suprarenal abdominal aorta cross sections from saline and Angll-treated mice. Bars: $100 \mu \mathrm{m}$ (top); $50 \mu \mathrm{m}$ (bottom and insets I and II). (A-E) Numbers of mice per group were 9 saline, 24 Angll, 9 CsA+Angll, and 7 CsA. Results were pooled from two independent experiments and are representative of four.

activation of the Rcan 1 promoter. A combination of a phorbol ester and calcium ionophore (PIo), used as a positive control (Cano et al., 2005),

Rcan 1 is expressed as two isoforms, Rcan1-1 and Rcan 1-4 (Genescà et al., 2003). Real-time quantitative PCR (qPCR) detected induced Rcan 1-4 mRNA expression 1 and $4 \mathrm{~h}$ after stimulation of VSMCs with AngII, and this was reduced almost to basal levels by pretreatment with CsA (Fig. 6 B). Similar results were obtained with rat aortic VSMCs (Fig. S3 A), demonstrating that regulation of Rcan1-4 expression by AngII is not exclusive to mouse cells. Rcan1-4 was barely detected in unstimulated mouse VSMCs but was strongly induced by AngII in a CsA-sensitive manner (Fig. 6 C). $\mathrm{AT}_{1} \mathrm{R}$ antagonist, but not $\mathrm{AT}_{2} \mathrm{R}$ antagonist, abolished induced expression of Rcan1-4 (Fig. 6 D). AngII-induced Rcan1-4 protein expression was also inhibited by infection with lentivirus encoding LxVP or VIVIT but not LxVPmutant (Fig. 6 E). Rcan1-1 was constitutively expressed (Fig. 6 C).

We next transfected mouse VSMCs with luciferase reporter vectors driven by an internal Rcan 1 promoter $(\mathrm{RCAN}(-350 /+83))$ or a derived sequence in which the NFAT interacting motif is mutated (RCAN $(-350$ / +83)mut; Minami et al., 2004). AngII-induced activation of the RCAN $(-350 /+83)$ reporter was strongly inhibited by CsA (Fig. 6 F). The $\mathrm{RCAN}(-350 /+83)$ mut reporter was barely affected by AngII stimulation (Fig. 6 F), suggesting that NFAT factor binding is required for AngII-mediated activated the wild-type promoter as much as AngII (Fig. 6 F). Similar results were obtained with rat aorticVSMCs (Fig. S3 B). These results indicate that AngII induces Rcan 1-4 mRNA expression via CN-NFAT activation.

To investigate whether Rcan1 plays a role in AngIIinduced VSMC migration, we examined the effect of AngII on aortic VSMCs derived from Rcan1-deficient mice (Porta et al., 2007). Western blotting confirmed the absence of Rcan1-1 and Rcan1-4 proteins in aortic tissue sections from Rcan $1^{-/-}$mice, whereas expression of both proteins was detected in AngII-stimulated Rcan $1^{+/+}$mice (Fig. S4 A). Rcan1 loss of function had no significant effect on NFATc4 phosphorylation status or subcellular localization, either in unstimulated VSMCs or cells activated with AngII or calcium ionophore (Fig. S4, B and C). Consistently, aortic tissue and VSMC extracts from Rcan1 $1^{+/+}$and Rcan1 $1^{-/-}$mice showed similar levels of CN activity toward the specific substrate RII phosphopeptide (Fig. S4 D). Moreover, the pattern of NFAT in vivo activation by AngII was similar in aortic tissues from Rcan $1^{+/+}$and Rcan1 ${ }^{-/-}$mice (Fig. S4 E). Together, these results strongly suggest that Rcan1 deficiency does not significantly affect CN activity in VSMCs. Rcan $1^{-/-}$VSMCs did not migrate in response to AngII in Transwell assays, whereas VSMCs of both genotypes responded similarly to fetal calf 


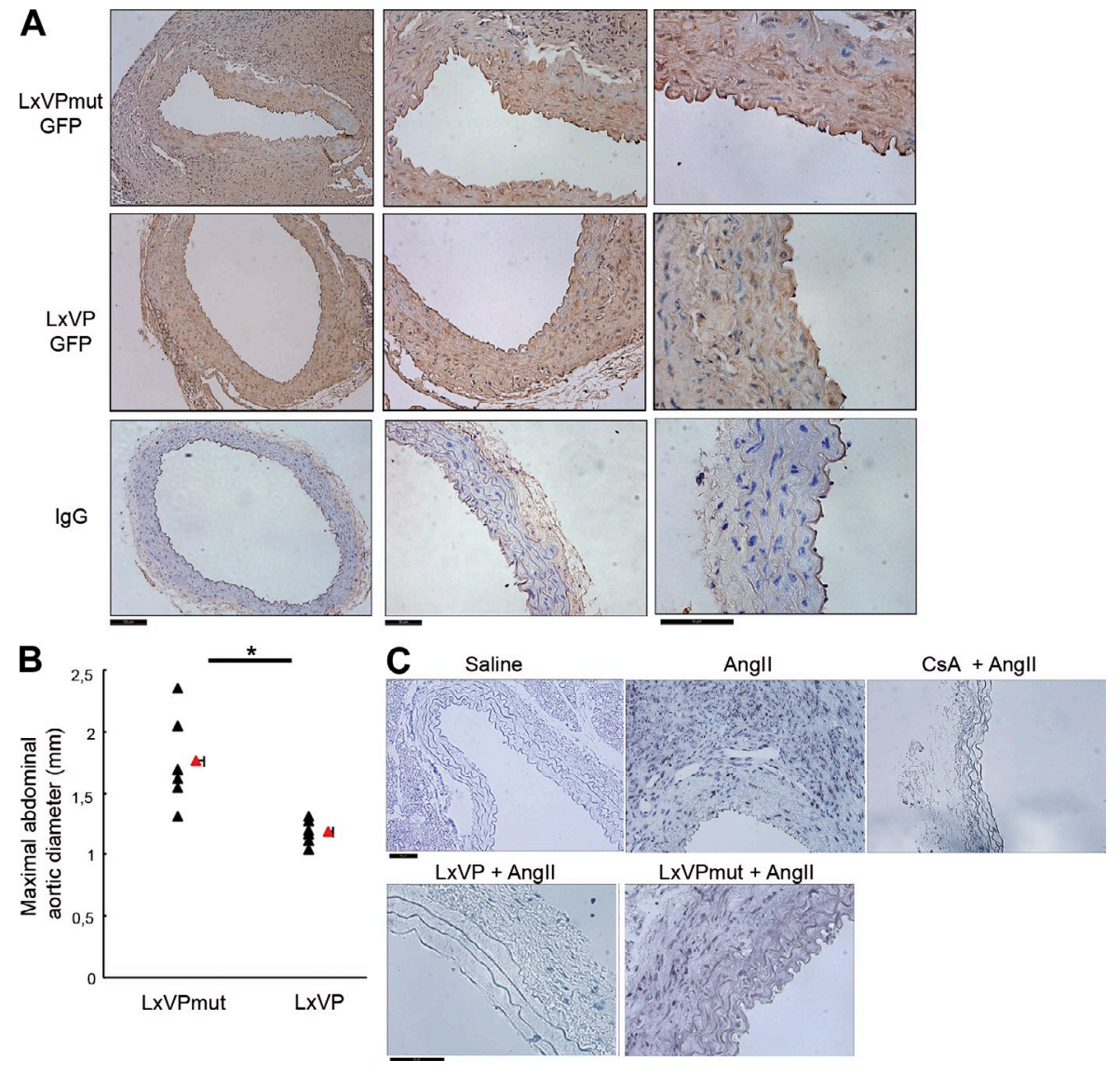

Figure 5. Systemic delivery of LxVP lentivirus inhibits development of Angllinduced AAA. (A) Mice were inoculated with lentivirus expressing GFP-tagged LxVP or LXVPmutant $100 \mu \mathrm{l}$ virus solution (1011 particles in $100 \mu \mathrm{l}$ ) injected directly into the right jugular vein 1 mo before staining of aortic sections. (A) GFP immunostaining in aortic sections. $\lg G$ staining serves as a negative control. Bars: $100 \mu \mathrm{m}$ (left); $50 \mu \mathrm{m}$ (middle and right). A representative experiment is shown of six performed in independent mice. (B) Apoe ${ }^{-1-}$ mice were inoculated with lentivirus expressing GFP-tagged LxVP or LxVPmutant 1 mo before minipumpinfusion of $1 \mu \mathrm{g} / \mathrm{kg} / \mathrm{min}$ Angll for $28 \mathrm{~d}$. Maximum suprarenal abdominal aortic diameter (in millimeters) is shown. Triangles and squares represent individual mice and means \pm SEM from six mice per condition, respectively. ${ }^{*}, \mathrm{P}<0.05$ versus LxvPmut. (C) Apoe ${ }^{-1-}$ mice were inoculated (bottom) or not (top) with lentivirus expressing GFP-tagged LxVP or LxVPmutant 1 mo before minipump infusion with $5 \mathrm{mg} / \mathrm{kg} / \mathrm{d}$ CsA $1 \mathrm{~d}$ before commencing similar administration with saline or $1 \mu \mathrm{g} / \mathrm{kg} / \mathrm{min}$ Angll for $14 \mathrm{~d}$. Aortic sections from these mice were analyzed by Southwestern histochemistry with NFAT probe. Bars, $50 \mu \mathrm{m}$. Representative images are shown of six mice per group. Results in A-C are representative of two independent experiments. serum, confirming that AngII-induced VSMC migration specifically requires Rcan1 (Figs. 7, A and B). Supporting these findings, AngII-stimulated Rcan $1^{+/+}$VSMCs efficiently reoccupied the denuded area in wound healing assays, whereas similarly treated Rcan 1-/- VSMCs did not (Fig. 7 C). The migratory response to AngII was rescued by adenoviral-mediated reexpression of Rcan1-4 in Rcan $1^{-/-}$VSMCs (Fig. $7 \mathrm{D}$ and Fig. S5).

\section{Rcan 1 mediates Angll-induced vascular damage}

We next analyzed the potential role of Rcan1 in the mouse models of AngII-induced restenosis and aneurysm. Rcan1 was detected in femoral artery sections after guidewire injury in AngII-treated mice (Fig. 8 A). Rcan1 expression was detected in the tunica media (Fig. 8 A) but, in some cases, could also be detected in neointimal cells (Fig. S6). The arteries of $\mathrm{Rcan} 1^{-/-}$mice were completely protected against the AngII-induced increase in intima thickness (Figs. 8, B and C), reflected in a near-basal level of stenosis (2.62 $\pm 2.5 \%)$. AngII thus appears to exacerbate neointima formation during vascular injury through the activation of $\mathrm{CN}$ and the induction of Rcan1-4 expression. Because $\mathrm{T}$ cells are also critical for neointima formation (Maiellaro and Taylor, 2007), we assessed their presence in femoral artery sections. $T$ cells were found in the adventitia of injured vessels distributed in a ringlike fashion around the external elastic (Fig. S6).
Rcan 1 was detected in the tunica media of aortic sections from control-treated Apoe ${ }^{-1-}$ mice, and its expression was notably increased in medial and adventitial cells of AAA sections from AngII-infused mice (Fig. 9 A and Fig. S7 A). Western blotting revealed a sharp increase in Rcan1-4 expression in this tissue (Fig. 9 A). Both medial and adventitial cells from AAA also expressed SMA, which was restricted to the tunica media in control tissues (Fig. 9 B and Fig. S7 A). Vimentin-positive cells were also found in the adventitia of control aortae and AAA, whereas CD3- and Mac3-positive cells were found in the adventitia of aneurysmal sections but not in control aortae (Fig. $9 \mathrm{~B}$ and not depicted).

To investigate the involvement of Rcan1 in AAA formation, we established Apoe ${ }^{-/-}$Rcan1-/- double-knockout mice and analyzed their response to AngII. In contrast to Apoe ${ }^{-/-}$Rcan $1^{+/+}$mice, abdominal aortae and tissue sections from

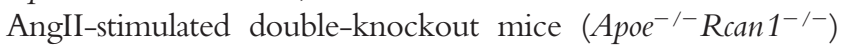
were almost indistinguishable from samples from salineinfused mice (Figs. 9, C-E). No significant wall remodeling was observed in abdominal aorta tissue sections from AngIItreated $A p o e^{-/-}$Rcan $1^{-/-}$mice (Fig. 9 E). These findings were reflected in a significantly lower maximal aortic diameter in Apoe ${ }^{-/-}$Rcan $1^{-/-}$mice compared with $A p o e^{-/-}$Rcan $1^{+/+}$mice (Fig. 9 F). Remarkably, whereas $82 \%$ of AngII-infused Apoe ${ }^{-/-}$ Rcan $1^{+/+}$mice developed AAA, no Apoe ${ }^{-/-} \mathrm{R}$ can $1^{-/-}$mice developed this condition. 
A Rcan

Cnn1
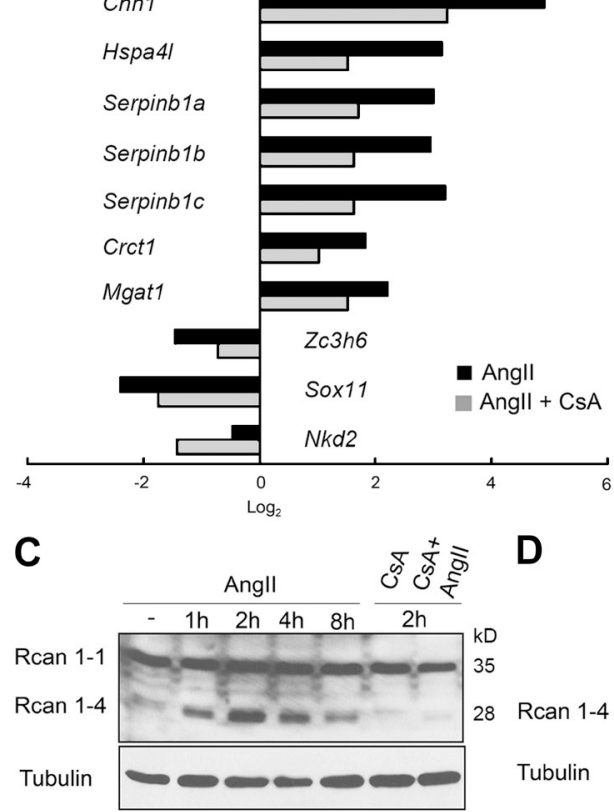

D
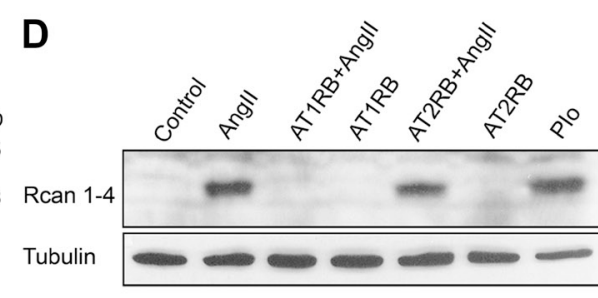

E
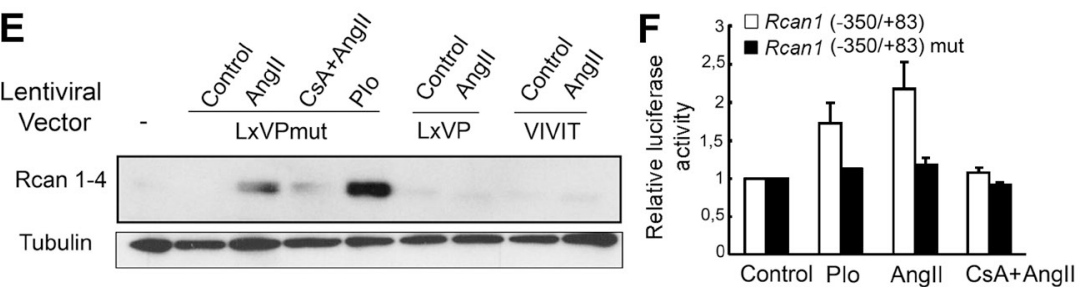

Figure 6. Angll induces $\mathrm{CN}$-dependent gene and protein expression of Rcan 1 in VSMCs. (A-D) VSMCs were stimulated with $1 \mu \mathrm{M}$ Angll after pretreatment for $1 \mathrm{~h}$ with $200 \mathrm{ng} / \mathrm{ml} \mathrm{CsA}, 1 \mu \mathrm{M}$ of the $\mathrm{AT}_{1}$ blocker ZD7155, or $10 \mu \mathrm{M}$ of the $\mathrm{AT}_{2}$ blocker PD123319. (A) RNA expression in VSMCs stimulated with Angll for $4 \mathrm{~h}$ after pretreatment or not with CsA was analyzed by hybridization of arrays. Expression of the indicated genes in the array under each experimental condition is shown as fold changes $\left(\log _{2}\right)$ relative to control cells ( $P<0.05$ vs. control).

(B) qPCR analysis of Rcan 1 mRNA expression after Angll treatment for 1 and $4 \mathrm{~h}$. mRNA amounts were normalized to Top expression and data are expressed as the fold change relative to nonstimulated cells. Means of triplicate qPCR determinations for each condition are shown from a representative experiment of five performed. (C) Time course Rcan 1 immunoblot in VSMCs treated as indicated. (D) Immunoblots showing the effect of $A T_{1}$ or $A T_{2}$ blockers on Angll-stimulated Rcan 1-4 expression. Plo, cells stimulated with a phorbol ester plus calcium ionophore A23187. (E) Immunoblots showing Rcan 1-4 expression in VSMCs infected with lentiviruses expressing GFP-tagged LxVP or LxVPmutant peptides and treated as indicated. (C-E) Tubulin expression was used as loading control. Representative experiments of four to six performed are shown. (F) Relative luciferase activity from VSMCs transfected with the indicated reporters and treated as indicated above. Plo treatment was used as a positive control. Values are means \pm SEM of triplicate luciferase determinations for each condition from five experiments.
Because Rcan1 was found in the adventitia and this layer contained hematopoietic cells, we investigated whether Rcan1 expression in these cells was critical for AngII-induced AAA. To this end, we transplanted Apoe $\mathrm{R}^{-/-} \mathrm{Ran}^{-/-}$or Apoe ${ }^{-/-}$ Rcan $1^{+/+}$bone marrow cells into irradiated Apoe ${ }^{-/-} \mathrm{R}$ can $1^{+/+}$ mice. After verification of successful engraftment 2 mo after transplantation (Fig. S7 B), we treated the mice with AngII for $28 \mathrm{~d}$. We found no gross differences in AAA formation between the two groups of transplanted mice (Fig. 9 G), suggesting that Rcan1 expression in leukocytes is not essential for AngII-induced aneurysm.

\section{DISCUSSION}

Our results provide evidence that CN-NFAT-mediated induction of Rcan1-4 plays a central role in AngII-induced artery obstruction and aortic aneurysm formation. Complementary approaches demonstrate that $\mathrm{CN}$ is required for AngII-induced Rcan1-4 expression, that Rcan1-4 is a key mediator of AngII-induced VSMC migration, and that CN and Rcan1 are both required for AngII-induced vessel remodeling in restenosis and aneurysm.

Although the mechanisms of AngII-induced remodeling in AAA and restenosis are different, our findings identify a common link. AngII promotes VSMC migration, a critical event for lesion development and progression in several vascular diseases (Casscells, 1992; Schwartz, 1995, 1997; Curci, 2009), and activates Rcan1-4 expression in neointima growth and aneurysm. We propose that CN-NFAT-activated induction of Rcan1-4 expression by AngII mediates migration of VSMCs during vascular remodeling, and we hypothesize that this migration might be essential for the onset of related pathologies such as neointima formation and AAA.

The growth-promoting effects of AngII on VSMCs are thought to contribute to the pathogenesis of various cardiovascular diseases. However, the evidence for growthpromoting effects of AngII on VSMCs is conflicting. Thus, although many groups have reported increased DNA synthesis in VSMCs treated with AngII (Watanabe et al., 2001; Sayeski and Ali, 2003; Nagata et al., 2004; Guo et al., 2009), some of these results showed that AngII did not increase cell number (Watanabe et al., 2001). Other groups even reported that AngII was not mitogenic in VSMCs (Geisterfer et al., 1988; Berk et al., 1989; Owens, 1989). Although our data show that AngII is a strong inducer of VSMC migration, we also found that it is only a very modest activator of VSMC proliferation (unpublished data), which is consistent with previous studies (Watanabe et al., 2001; Guo et al., 2009). However, because Angll induces the synthesis of potent mitogens such as PDGF (Naftilan et al., 1989) or ET-1 (Emori et al., 1989; Scott-Burden et al., 1991), it might 

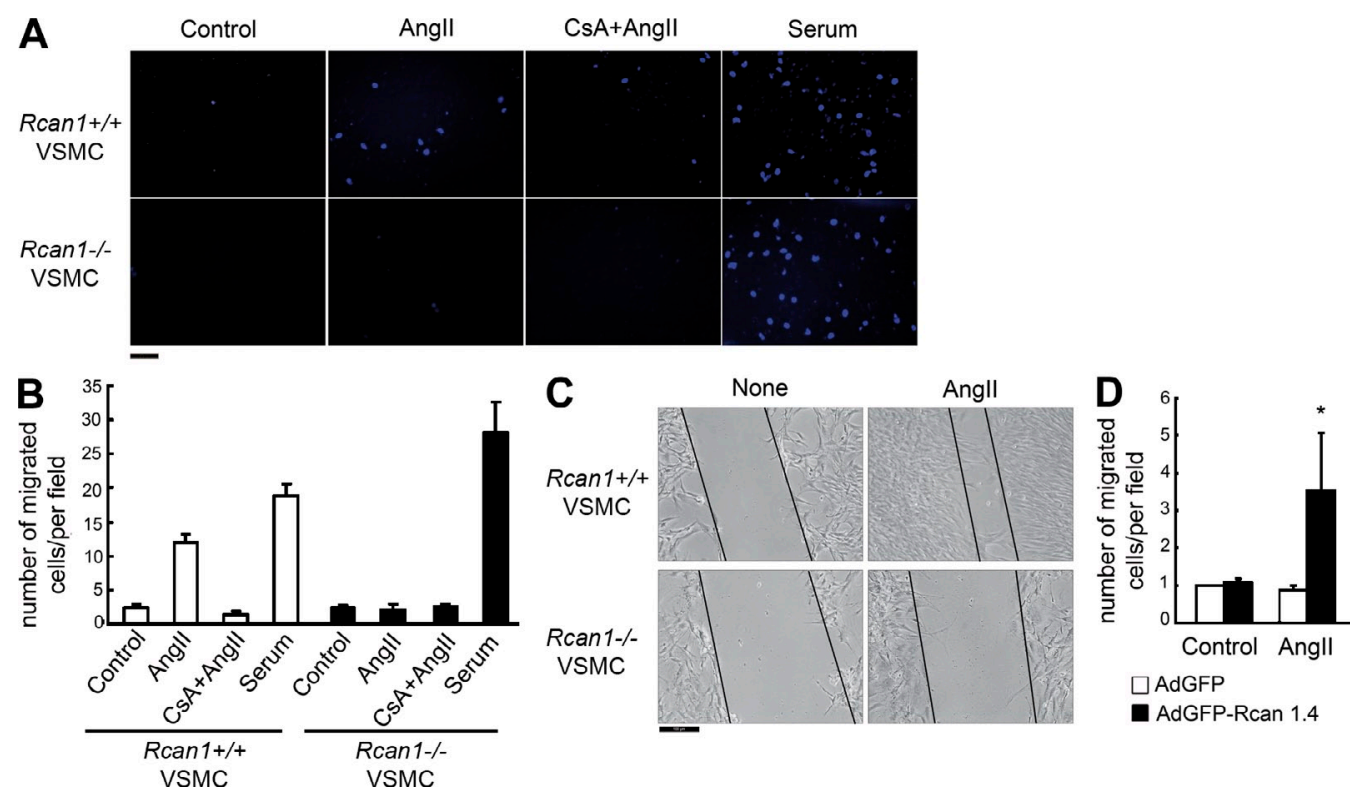

Figure 7. Rean 1 is required for Angll-induced VSMC migration. (A and B) $R c a n 1^{+/+}$and $R$ can $1^{-/-}$VSMCs were seeded on the upper surface of chemotaxis (Transwell) chambers containing no stimulus, $1 \mu \mathrm{M}$ Angll, $1 \mu \mathrm{M}$ Angll plus $200 \mathrm{ng} / \mathrm{ml} \mathrm{CsA}$, or 10\% FBS (Serum) in the lower chamber. After $4 \mathrm{~h}$, nonmigrating cells were removed from the upper filter surfaces and the filter was stained with Hoechst. (A) Representative images of the lower filter surface. Bar, $50 \mu \mathrm{m}$. (B) Quantification of migrated VSMCs in 10 fields per condition in a representative transwell experiment of six to seven performed (means \pm SEM). (C) Representative images of a wound-healing assay of four performed with Rcan $1^{+/+}$and $R$ can $1^{-/-}$VSMCs treated as indicated. Lines mark the wound limits after $4 \mathrm{~h}$. Bar, $100 \mu \mathrm{m}$. (D) Quantification of migrated Rcan 1-/- VSMCs infected with Ad-GFP or Ad-Rcan1-4 and treated as indicated. Cells were counted in 10 fields per condition. Data are means \pm SEM of three independent experiments. ${ }^{*}, \mathrm{P}<0.05$ versus control.

indirectly potentiate VSMC proliferation in vivo. Whether Rcan1 participates in AngII-induced VSMC growth remains to be determined.

Medial VSMCs are not the only cells participating in AngII-induced vascular remodeling. Endothelial cells from the intima layer and adventitial cells also play essential roles during pathological remodeling. The adventitia, in particular, has recently received considerable attention. Changes in its cellular components and its size have been reported in animal models of restenosis (Maiellaro and Taylor, 2007). In addition, the pathogenesis of AAA has been shown to initiate with macrophage recruitment into the adventitia (Gavrila et al., 2005), which is followed by additional lymphocyte and macrophage infiltration during its development (Daugherty et al., 2000). Adventitial fibroblasts become activated during vessel remodeling and stay in the adventitia as nonmigratory, but
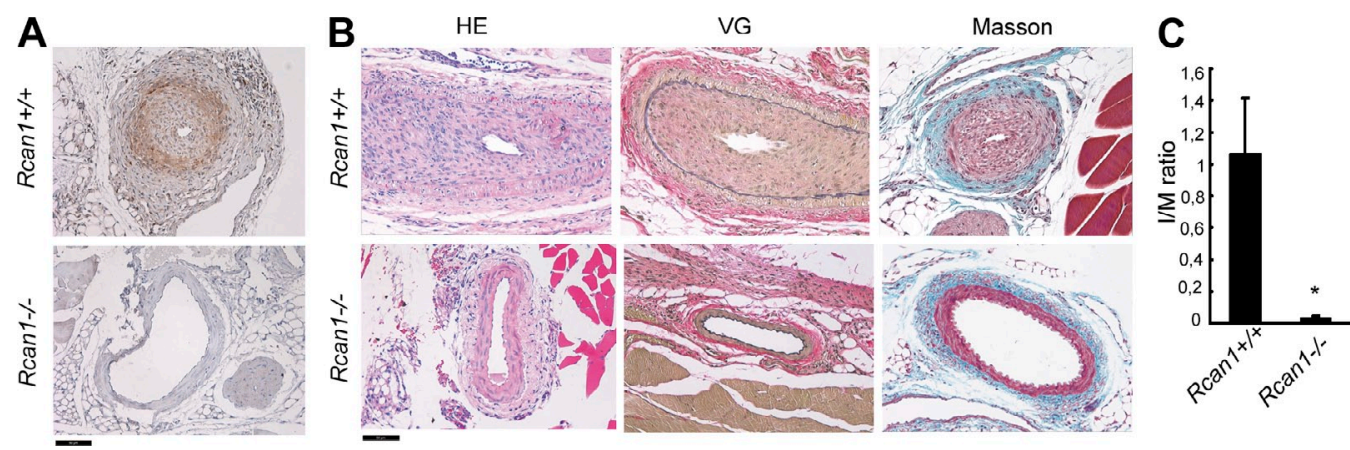

Figure 8. Rean 1 mediates Angll-induced neointima formation. The left femoral artery was wire injured and Angll was administrated by subcutaneous minipump infusion during $14 \mathrm{~d}$. CsA administration commenced $24 \mathrm{~h}$ before treatment with Angll and continued throughout the Angll infusion period. (A) Representative Rcan 1 immunostaining of left femoral artery cross sections from Angll-treated Rcan $1^{+/+}$and $R$ can $1^{-/-}$mice $(n=5 / g r o u p)$. Bar, $50 \mu \mathrm{m}$. (B) Images of femoral artery cross sections from Angll-treated Rcan $1^{+/+}$and Rcan $1^{-1-}$ mice stained with hematoxylin-eosin (HE), Van Gieson (VG), and Masson's trichrome stains. Bar, $50 \mu \mathrm{m}$. Representative experiments are shown of 8-11 performed. (C) Quantification of the I/M ratio between groups. Data are means \pm SEM. Mice per group were 8 Rcan $1^{++}$Angll and 11 Rcan $1^{-1-}$ Angll. ${ }^{*}, \mathrm{P}<0.05$ versus Rcan $1^{+\mid+}$Angll. Results in $\mathrm{A}$ and $\mathrm{B}$ are representative of two independent experiments. Pooled data from two independent experiments are shown in $C$. 
A
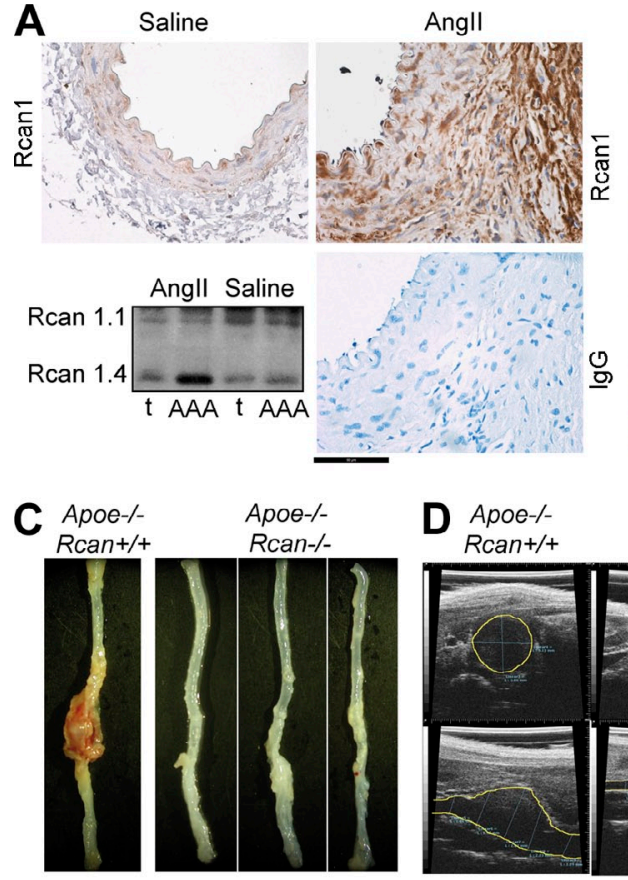

Apoe-/-
Rcan+/

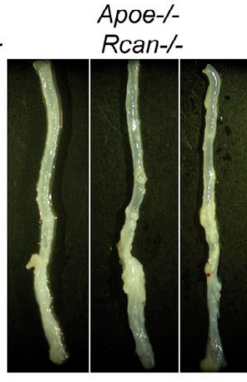

$\mathbf{F}$
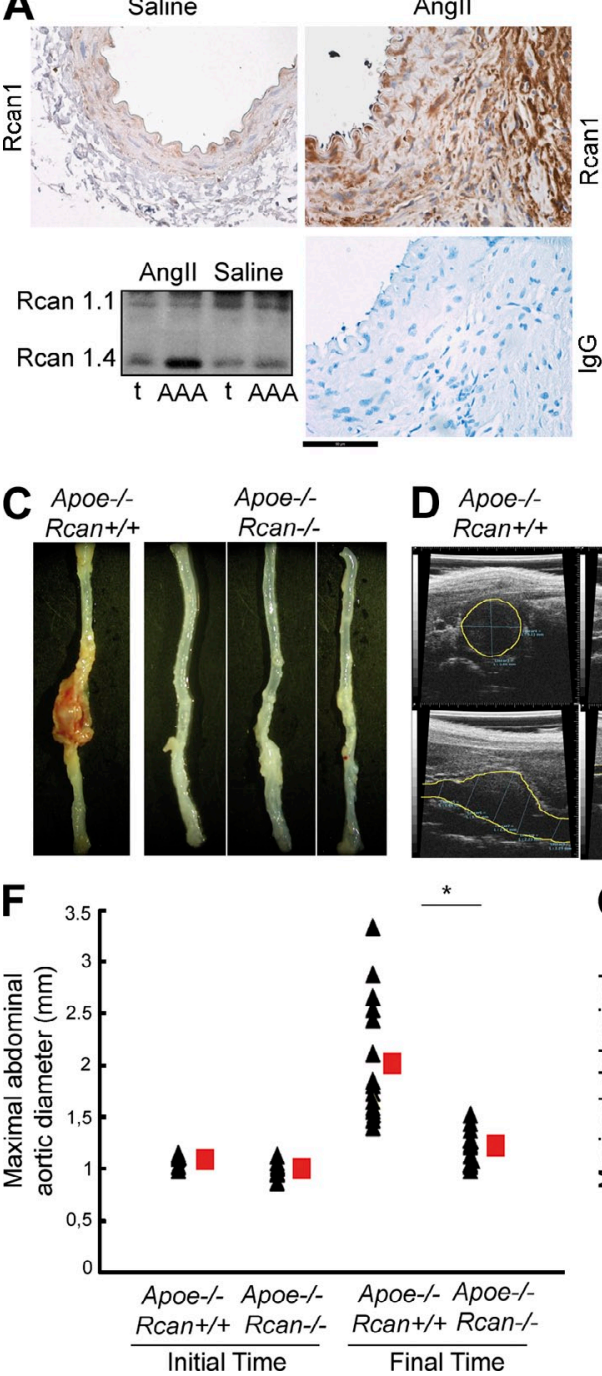

9
B
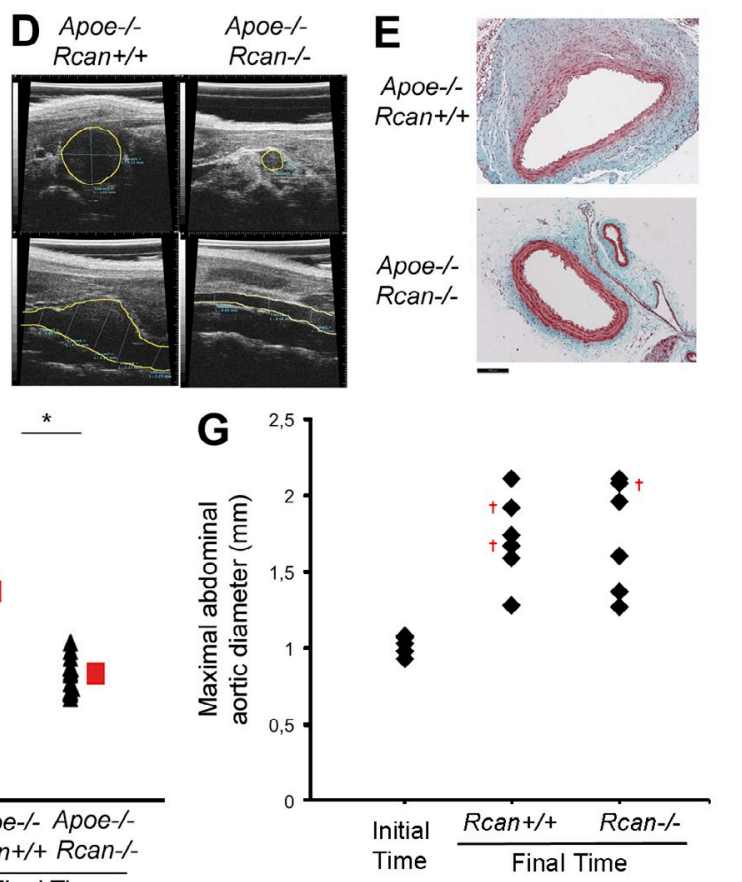

proliferating, fibroblasts, or are phenotypically converted into smooth muscle-like cells named myofibroblasts (Sartore et al., 2001). Of note, both myofibroblasts and activated VSMCs express SMA and SM22 (Sartore et al., 2001). Conversely, medial VSMCs, when activated in the course of vascular remodeling, display structural and functional features common to immature, developmentally related cells that are hardly distinguishable from myofibroblasts (Owens, 1995; Sartore et al., 1999).

We detected activated NFAT and Rcan1 expression in VSMCs, endothelium, and adventitial cells. In the adventitia of AAA sections, CD3- and Mac3-positive cells were readily detected, indicating the presence of $\mathrm{T}$ lymphocytes and macrophages. In addition, other adventitial cells were positive for vimentin or SMA expression, suggesting the presence of fibroblasts, myofibroblasts, or activated VSMCs. We also found numerous cells double positive for SMA and Rcan1 in media and adventitia of AAA sections, but it is likely that Rcan1 is also expressed in infiltrating leukocytes and vimentin-positive cells. Rcan1 expression in any of these cells could potentially be critical for pathological vessel remodeling. However, because

deletion of Rcan1 in hematopoietic cells does not prevent AngII-induced AAA, Rcan1 expression in these cells does not seem to be critical for AAA formation. Given that AngII-elicitedVSMC migration requires Rcan 1 expression and that VSMC migration is central to vessel remodeling, we propose that Rcan1 expression in VSMCs or myofibroblasts is critical for vascular remodeling in vasculopathies. However, we do not exclude that its expression in endothelial cells or proliferating fibroblasts might also contribute to this remodeling.

RCAN1 was originally identified as a negative regulator of CN activity (Rothermel et al., 2000; Davies et al., 2007), but other studies suggest that it might not always have this effect (Kingsbury and Cunningham, 2000; Vega et al., 2003). It may be that regulation of CN activity by Rcan1 depends on cell type, tissue, or stimulus, or that Rcan1 inhibits $\mathrm{CN}$ only at specific developmental or disease stages. In this regard, phosphorylation of Rcan1 converts it from inhibitor 
to facilitator of CN-NFAT signaling (Liu et al., 2009; Shin et al., 2011). We found that CN activity was not significantly affected in VSMCs or aortic tissue from Rcan $1^{-1-}$ mice. Thus, using the RII phosphopeptide as a specific substrate, CN activity was similar in VSMCs and aortic tissue extracts from $R c a n 1^{+/+}$or Rcan $1^{-/-}$mice. In addition, Rcan 1 deficiency did not affect the basal level of NFAT dephosphorylation, its subcellular localization, or its DNA binding capacity, or the changes to these parameters induced by AngII in VSMCs or aortic tissues. Together, these data indicate that $\mathrm{CN}$ does not mediate Rcan1-dependent regulation of VSMC migration and pathological vascular remodeling. It may thus be that Rcan1 regulates vascular wall remodeling through interaction with other proteins. In this regard, known RCAN1-interacting proteins relevant to gene activation include Raf-1 (Cho et al., 2005), 14-3-3 (Abbasi et al., 2006), and NF-kB-inducing kinase (Lee et al., 2008).

The precise mechanism of neointimal growth in restenosis is not clear. AngII greatly exacerbates neointima growth of injured rat arteries (Schwartz et al., 1995; van Kleef et al., 1996), and a role in AngII-induced remodeling in rat arteries was recently reported for Akt (Li et al., 2005). However, although the CN-NFAT axis is implicated in neointimal growth induced by balloon injury (Satonaka et al., 2004; Liu et al., 2005), there have been no studies linking these actions of AngII and CN-NFAT signaling. In this study, using a femoral artery injury model in mice, we show that CsA inhibits not only the vascular remodeling caused by guidewire injury but also the sharply exacerbated damage caused by AngII. More importantly, our data provide further insight into how $\mathrm{CN}$ mediates AngII-induced damage. The identification of Rcan 1-4 as a CN-sensitive AngII-activated gene in VSMCs, together with the protection of $R \operatorname{can} 1^{-1-}$ mice against AngII-induced restenosis, indicates that Rcan1-4 is a key mediator of AngII-induced wall remodeling in this model of restenosis.

AAA, another example of pathological vascular remodeling, is also potently induced by AngII, although again the mechanisms are unclear. A recent study showed that cyclophilin A secreted by VSMCs mediates AngII-induced AAA formation in $A p o e^{-1-}$ mice (Satoh et al., 2009). CsA binds cyclophilin A, and it is this complex, not cyclophilin A alone, which binds CN and inhibits its activity (Liu et al., 1991). Inhibition of AAA by CsA could thus involve blockade of cyclophilin A secretion, interference in its activity, or inhibition of $\mathrm{CN}$. However, because the LxVP peptide inhibits $\mathrm{CN}$ phosphatase activity independently of cyclophilin $\mathrm{A}$, an effect of CsA on $\mathrm{CN}$ phosphatase activity seems more likely.

Many complex signaling pathways are stimulated after binding of AngII to its cell surface receptors. AngII-activated pathways include those mediated by diacylglycerol and protein kinase C; Janus kinase 2 and members of the signal transducer and activator of transcription family; the Src kinase family and its downstream effectors Akt and mitogen-activated protein kinases; and phospholipases PLD and PLA2, which induce the production of reactive oxygen species. In addition,
AngII elicits the formation of inositol-triphosphate $\left(\mathrm{IP}_{3}\right)$, which leads to $\mathrm{Ca}^{2+}$ accumulation in the cytosol and $\mathrm{CN}$ activation. Activation of these multiple pathways regulates the expression of numerous genes. Indeed, we have found that a very large number of genes is regulated by AngII in VSMCs (unpublished data). Remarkably, only 11 of these genes were sensitive to CsA and therefore regulated by CN. Moreover, only one of these genes, Rcan1, was inhibited by CsA by $>70 \%$. The RT-PCR and other in vitro data confirm that this inhibition relates to the isoform Rcan1-4. Using pharmacological inhibitors of $\mathrm{CN}$ and lentiviral delivery of CNinhibitory peptides, we show that, among the numerous signaling cascades triggered by AngII, that mediated by $\mathrm{IP}_{3}-$ $\mathrm{Ca}^{2+}-\mathrm{CN}$ is critical for Rcan1-4 induction and VSMC migration. Moreover, Rcan1-deficient mice, including newly generated $A p o e^{-/-}$Rcan $^{-1-}$ double knockouts, were protected against AngII-induced vessel remodeling. These results strongly argue for a specific action of CN-NFAT/Rcan1-4 signaling in the AngII response and provide strong evidence that, despite the clear differences between restenosis and aneurysm, CN-NFAT-induced Rcan1-4 expression is central to the mechanism of AngII-induced vascular damage and indicate that restenosis and AAA share mechanistic features.

Our findings might provide the basis for nonsurgical therapies to prevent restenosis and inhibit aneurysm growth. Although the introduction of drug-eluting stents has improved the prevention and treatment of restenosis (Iakovou et al., 2005), an 8-17\% neointimal obstruction persists in most cases (Waseda et al., 2009). Moreover, the entrapped immunosuppressive and cytostatic agents are relatively nonspecific (Marx and Marks, 2001; Bhatia et al., 2004) and are associated with late-stent thrombosis (Iakovou et al., 2005). Regarding human AAA, surgical repair is considered appropriate for large aneurysms, but the overall 30-d mortality is 5\% (Sakalihasan et al., 2005). Although pharmacological control of blood pressure, diabetes, hyperlipidemia, and other atherosclerotic risk factors can slow AAA growth in some cases (Chaikof et al., 2009), there is as yet no definitive treatment to prevent the progression of small aneurysms. More efficient therapies are therefore required for both pathologies.

Although pharmacological inhibition of $\mathrm{CN}$ with CsA prevents AngII-induced neointima formation and aneurysm development in our mouse models, its therapeutic use in humans for related diseases would require careful evaluation because of its severe side effects, which include neurotoxicity, diabetes, nephrotoxicity, and hypertension. CsA disrupts $\mathrm{CN}$ phosphatase activity and thus affects all downstream signal transduction pathways. This broad action might explain some of its undesired side effects and toxicity. Moreover, CsA toxicity is at least partly independent of CN (Kiani et al., 2000; Martínez-Martínez and Redondo, 2004). A more specific inhibition of the CN-NFAT pathway can potentially be achieved with $\mathrm{CN}$-interacting peptides, but although these peptides are more selective than CsA, they also inhibit CN phosphatase activity or block its interaction with other substrates (Aramburu et al., 1999; Martínez-Martínez et al., 2006). 
The identification of effector molecules downstream from $\mathrm{CN}$ might facilitate the development of even more selective molecules for use in drug-eluting stents or to prevent AAA expansion. Rcan1-4, which appears to act downstream of CN, might be a more promising target than CN. Strategies aimed at locally regulating Rcan1-4 function or expression might therefore prove to be more specific and less toxic than current interventions for inhibiting restenosis and AAA growth.

\section{MATERIALS AND METHODS}

Animal experimental design. Animal procedures were approved by the CNIC's Ethics Committee and conformed to European Union guidelines for the care and experimental use of animals. Rcan $1^{-1-}$ mice were as previously described (Porta et al., 2007). Double-knockout Apoe ${ }^{-/-}$Rcan 1 $1^{-1-}$ mice were generated by crossing $A p o e^{-/-}$mice (Charles River) with $R c a n 1^{-/-}$ mice. All mice were genotyped by PCR of tail samples using the following primers: Rcan1, 5'-GGTGGTCCACGTGTGTGAGA-3', 5'-ACGTGAACAAAGGCTGGTCCT-3', and 5'-ATTCGCAGCGCATCGCCTTCTATCGCC-3'; and Apoe, 5' -TGTCTTCCACTATTGGCTCG-3' and 5'-TGGCGGACCGCTATCAGGAC-3'. Control littermates were used in all experiments.

2-mo-old mice were administered with various compounds by subcutaneous osmotic minipump infusion (Alzet Corp) as described previously (Esteban et al., 2004). AngII (Sigma-Aldrich) was administrated at $1 \mu \mathrm{g} / \mathrm{kg} / \mathrm{min}$ during $28 \mathrm{~d}$ in AAA experiments and at $0.5 \mu \mathrm{g} / \mathrm{kg} / \mathrm{min}$ during $14 \mathrm{~d}$ in femoral artery injury experiments. The $\mathrm{AT}_{1} \mathrm{R}$ blocker losartan (Fluka) was administered at $10 \mathrm{mg} / \mathrm{kg} / \mathrm{d}$ and the $\mathrm{AT}_{2} \mathrm{R}$ blocker PD123319 (Sigma-Aldrich) at $30 \mathrm{mg} / \mathrm{kg} / \mathrm{d}$. Mini pumps loaded with angiotensin receptor blockers or CsA (Sandimmun; Novartis; $5 \mathrm{mg} / \mathrm{kg} / \mathrm{d}$ ) were implanted $24 \mathrm{~h}$ before implantation of mini pumps containing AngII. Control animals were infused with saline. Endoluminal injury to the common femoral artery was performed by three passages of a $0.25-\mathrm{mm}$ diameter angioplasty guidewire (Advanced Cardiovascular Systems) as previously described (Roque et al., 2000). Mini pumps for administration of AngII were fitted immediately before injury. Stenosis was calculated using the following equation: \% stenosis $=100 \times$ [Intimal area/(Lumen area + Intimal area)]. Abdominal aortic diameter was monitored by high-frequency ultrasound with the VEVO770 system as previously described (Martin-McNulty et al., 2005). Abdominal aortas with external diameters of $\geq 1.5 \mathrm{~mm}$ were considered to contain an AAA. For jugular lentiviral inoculation experiments, animals were inoculated with $100 \mu \mathrm{l}$ virus solution $\left(10^{9}\right.$ particles/ $\mu \mathrm{l}$ in DME/20\% FBS) injected directly into the right jugular vein 1 mo before mini pump implantation. Infection efficiency was monitored by GFP immunohistochemistry.

For bone marrow transplantation, bone marrow-derived cells were obtained from the tibias and femurs of donor $A p o e^{-/-} R \operatorname{can} 1^{-/-}$or $A p o e^{-1-}$ Rcan $1^{+/+}$mice. Cells $\left(10^{7}\right.$ in $\left.300 \mu \mathrm{PBS}\right)$ were injected into the tail vein of 2-mo-old $A$ poe $e^{-/-}$Rcan $1^{+/+}$recipient mice lethally irradiated with 9 Gy. Engraftment success was verified $8 \mathrm{wk}$ after transplantation by PCR analysis on blood samples with the same primers used for tail genotyping. AAA was then induced by infusion of AngII as described in the previous paragraph.

Cellular procedures. Segments of abdominal and thoracic aortas were dissected from 12-wk-old male C57/BL6 mice or Wistar rats (Charles River). Aortas were immersed in PBS, and fat and connective tissue were rapidly removed with fine forceps. The aortas were incubated for $45 \mathrm{~min}$ at $37^{\circ} \mathrm{C}$ in a 95\% air, 5\% $\mathrm{CO}_{2}$ atmosphere in serum-free DME (Invitrogen) containing $2 \mathrm{mg} / \mathrm{ml}$ collagenase type 2 , L-glutamine, and antibiotics (100 units/ml penicillin and $100 \mu \mathrm{g} / \mathrm{ml}$ streptomycin). Aortas were then cut into small rings, and individual explants were seeded in DME containing 10\% (rat) or $20 \%$ (mouse) FBS (Lonza). Explants were not disturbed during the first week. After outgrowth of adherent cells, cultures were trypsinized and subcultured. All experiments were performed during passages 3-7. Before stimulation, cells were rendered quiescent for $48 \mathrm{~h}$ by incubation in serum-free medium. AngII $\left(10^{-6} \mathrm{M}\right)$, AT2RB (PD123319; $\left.10^{-5} \mathrm{M}\right)$, and $10 \mathrm{ng} / \mathrm{ml} \mathrm{PMA} \mathrm{were}$ obtained from Sigma-Aldrich. $1 \mu \mathrm{M}$ calcium ionophore A23187 (Io), $10^{-6} \mathrm{M}$ AT1RB (ZD-7155 hydrochloride), and $200 \mathrm{ng} / \mathrm{ml}$ CsA were obtained from EMD, Tocris Bioscience, and LD laboratories, respectively. Cells were transfected by the Lipofectamine PLUS (Invitrogen) method. VSMCs were infected with lentiviruses expressing $3.3 \times 10^{8} \mathrm{pfu} / \mathrm{ml}$ GFP-peptide fusion proteins or adenoviruses expressing either GFP-tagged Rcan1 (AdenoRcan1) or GFP (Adeno-GFP; $1.6 \times 10^{8} \mathrm{pfu} / \mathrm{ml}$ ). Infection efficiency was monitored by flow cytometry (FACSCanto; BD).

VSMCs were transfected using Lipofectamine PLUS with a luciferase reporter driven by the RCAN1-4-intronic promoter (-350/+83 DSCRluc; provided by T. Minami, Research Center for Advanced Science and Technology, University of Tokyo, Tokyo, Japan) or its mutant version. Cells were left to recover in complete medium for $1 \mathrm{~d}$ and were then serum deprived for $48 \mathrm{~h}$, stimulated for $4 \mathrm{~h}$, and lysed. Luciferase activity was detected with the Luciferase Assay System (Promega).

VSMCs in DME containing $0.1 \%$ BSA were seeded $\left(5 \times 10^{4}\right.$ per well $)$ onto 8 - $\mu \mathrm{m}$ pore Transwell 24 -well cell culture inserts (Costar). The lower wells of the chemotaxis chambers were filled with $1 \mathrm{ml}$ DME $(0.1 \%$ BSA) containing $10^{-6} \mathrm{M}$ AngII, $10^{-6} \mathrm{M}$ AngII plus $200 \mathrm{ng} / \mathrm{ml} \mathrm{CsA}$, or $10 \%$ FBS. After $4 \mathrm{~h}$, nonmigrating cells were removed from the upper filter surfaces, and the filter was washed, fixed with $4 \%$ paraformaldehyde, and stained with Hoechst. Migrated cells were counted on photographs of 10 randomly selected fields on the lower surface of the filters. Experiments were performed in duplicate. For wound closure assays, Rcan $1^{+/+}$or Rcan $1^{-/-}$VSMCs were grown to confluence in growth medium and then serum deprived for $24 \mathrm{~h}$. A single scrape wound was made, and cells were then incubated with or without $10^{-6} \mathrm{M}$ AngII. Migration into the denuded area was monitored by photomicroscopy.

For immunofluorescence of cultured VSMCs, cells seeded onto coverslips were subjected to different treatments, fixed with 3\% paraformaldehyde, permeabilized with $0.1 \%$ Triton-X-100, and then stained with anti-NFATc4 (1/1000; Santa Cruz Biotechnology, Inc.), followed by Alexa Fluor 488-labeled secondary antibody. As a negative control, species- and isotype-matched $\operatorname{IgG}$ were used in place of the primary antibody.

Lentiviral and adenoviral production and infection. Lentiviruses expressing GFP-tagged LxVP, LxVPmutant, and VIVIT peptides were obtained by transient calcium phosphate transfection of HEK-293 cells, using a three plasmid HIV-derived and VSV pseudotyped lentiviral system provided by M.K. Collins (University College London, London, England, UK). The supernatant containing the lentiviral particles was collected $48 \mathrm{~h}$ after removal of the calcium phosphate precipitate, filtered through a $45-\mu \mathrm{M}$ PVDF membrane (Steriflip; Millipore), and ultracentrifuged for $2 \mathrm{~h}$ at $26,000 \mathrm{rpm}$ at $4^{\circ} \mathrm{C}$ (Ultraclear Tubes, SW28 rotor, and Optima L-100 XP Ultracentrifuge; Beckman Coulter). Viruses were resuspended in cold sterile DME solution and titrated in Jurkat cells by flow cytometry. Infection efficiency (GFP-expressing cells) and cell death (propidium iodide staining) were monitored by flow cytometry. Similar infection efficiencies with the different constructs were found across experiments.

Adenovirus encoding GFP-tagged Rcan1 (Adeno-Rcan1) and control GFP adenovirus (Adeno-GFP) were as previously described (Minami et al., 2004). Adenovirus infection was performed on $1.6 \times 10^{8} \mathrm{pfu} / \mathrm{ml}$ of subconfluent primary VSMCs, and expression of the encoded protein was monitored by immunoblotting and flow cytometry.

Histological analysis. Aortas were fixed by perfusing with 4\% paraformaldehyde. 5- $\mu \mathrm{m}$ paraffin cross sections from fixed aortas were stained with hematoxylin-eosin, Masson's trichrome, orVan Gieson stains or were used for immunohistochemistry or immunofluorescence. The following antibodies were used for immunohistochemistry or immunofluorescence: anti-Rcan1 (1/50; Sigma-Aldrich), anti-GFP (1/100; Invitrogen), anti- $\alpha-S M A(1 / 300$; Sigma-Aldrich), anti-CD3 (1/200; Dako), anti-Mac3 (1/200; Santa Cruz Biotechnology, Inc.), and anti-vimentin (1/50; Abcam). Sections were treated as previously described (Roque et al., 2000). For GFP, CD3, and Rcan1 immunohistochemistry, color was developed with diaminobenzidine (DAB; Vector Laboratories), and sections were then counterstained with hematoxylin, dehydrated, and mounted in DPX (Fluka). For $\alpha$-SMA 
immunohistochemistry, color was developed with either DAB or Fast-Red Alkaline Phosphatase Substrate Tablets (Sigma-Aldrich). Specificity was tested by substitution of primary antibody with nonrelated IgG.

For in situ southwestern histochemistry, $5-\mu \mathrm{m}$ transverse aorta sections were deparaffinized through xylene and alcohols and rehydrated. Sections were then fixed with $0.5 \%$ paraformaldehyde in PBS for $25 \mathrm{~min}$ at $28^{\circ} \mathrm{C}$, and endogenous alkaline phosphatase was quenched with $5 \mathrm{mM}$ levamisole (Sigma-Aldrich). Preparations were then digested with 0.5\% pepsin A (SigmaAldrich) in $1 \mathrm{~N} \mathrm{HCl}$ for $35 \mathrm{~min}$ at $37^{\circ} \mathrm{C}$ and washed twice with HEPES/BSA buffer (10 mM HEPES, $40 \mathrm{mM} \mathrm{NaCl}, 10 \mathrm{mM} \mathrm{MgCl} 2,1 \mathrm{mM}$ dithiothreitol [DTT], $1 \mathrm{mM}$ EDTA, and $0.25 \% \mathrm{BSA}, \mathrm{pH}$ 7.4). Sections were incubated with $0.1 \mathrm{mg} / \mathrm{ml}$ DNase I in buffer 1 for $30 \mathrm{~min}$ at $30^{\circ} \mathrm{C}$. Activated NFAT proteins were probed with the synthetic sense DNA sequence $5^{\prime}$-GATCGCCCAAAGAGGAAAATTTGTTTCATACAG-3'. This sequence contains a composite site comprising the NFAT and AP1 sites from the mouse IL-2 promoter (Jain et al., 1993). The NFAT probe was labeled with digoxigenin (Sigma-Aldrich) and diluted to $25 \mathrm{pM}$ in buffer 1 (0.1 M maleic acid and $0.15 \mathrm{M} \mathrm{NaCl}, \mathrm{pH} 7.5$ ) containing $0.5 \mathrm{mg} / \mathrm{ml}$ poly (dI-dC; Sigma-Aldrich). The following negative controls were used: (1) absence of probe; (2) mutant NFAT probe (sense 5'-GATCGCCCAAAGACCTTAATGGACTTCATACAG-3'), (3) NFKB probe (sense 5'-GATCAGTTGAGGGGACTTTCCCAGGC- $3^{\prime}$ ); and (4) competition assay, in which sections were incubated with a 200-fold excess of unlabeled NFAT probe before application of the labeled probe. After overnight incubation at $37^{\circ} \mathrm{C}$ in a humidified chamber, sections were washed twice with wash buffer $(0.03 \%$ Tween 20 in buffer 1$)$ and were then incubated $1 \mathrm{~h}$ in blocking solution $(0.1 \%$ SSC and $0.1 \%$ SDS diluted 1:10 in washing buffer). The preparations were washed once more with washing buffer and incubated for $2 \mathrm{~h}$ at $37^{\circ} \mathrm{C}$ with an anti-digoxigenin antibody conjugated to alkaline phosphatase (1:200 in blocking solution; Roche). Next, sections were washed in washing buffer and in buffer 3 (Tris$\mathrm{HCl} 0.1 \mathrm{M}, 0.1 \mathrm{M} \mathrm{NaCl}$, and $50 \mathrm{mM} \mathrm{MgCl}$, $\mathrm{pH} 9.5$ ) at room temperature. Bound alkaline phosphatase was visualized with nitroblue tetrazolium chloride and 5-bromo-4-chloro-3-indolyl-phosphate (NBT/BCIP; Roche). The reaction was stopped by incubation in TE buffer $(10 \mathrm{mM}$ Tris and $1 \mathrm{mM}$ EDTA, $\mathrm{pH}$ 8.0), and sections were dehydrated through a graded ethanol series and mounted in $50 \%$ glycerol in PBS.

All images except those from immunofluorescence assays were acquired at room temperature using a microscope (DM2500; Leica) with 10, 20, or $40 \times$ HCX PL Fluotar objective lenses and acquisition software (Leica Application Suite V3.5.0). Images were processed for presentation with Photoshop (Adobe) according to the guidelines of this Journal. Immunofluorescence images were acquired using an inverted confocal microscope (LSM700; Carl Zeiss) with a $40 \times$ Plan-Apochromatic oil immersion objective and were normalized for each color separately. Presented confocal images are twodimensional maximal projections of a z-series through the cell depth. Images were processed for presentation with Zen 2009 Light Edition (Carl Zeiss) and Photoshop according to the guidelines of this Journal.

Immunoblot analysis. After stimulation, cells were washed with ice-cold PBS and lysed with $20 \mathrm{mM}$ Hepes, pH 7.6, containing $0.4 \mathrm{M} \mathrm{NaCl}, 1 \mathrm{mM}$ EDTA, $3 \mathrm{mM}$ EGTA, $1 \mu \mathrm{M}$ dithiothreitol, $1 \mathrm{mM}$ phenylmethylsulfonyl fluoride, $100 \mu \mathrm{M}$ benzamidine, $1 \mu \mathrm{g} / \mathrm{ml}$ pepstatin, $1 \mu \mathrm{g} / \mathrm{ml}$ aprotinin, and $1 \%$ Triton X-100. Lysates were incubated on a rocking platform for $15 \mathrm{~min}$ at $4^{\circ} \mathrm{C}$ and centrifuged at $14,000 \mathrm{~g}\left(15 \mathrm{~min}, 4^{\circ} \mathrm{C}\right)$. Supernatants were then collected, $2 \times$ Laemmli buffer was added, and extracts were boiled for $10 \mathrm{~min}$. Proteins were separated under reducing conditions on SDS-polyacrylamide gels ( $6 \%$ for NFAT or $12 \%$ for RCAN) and transferred to nitrocellulose membranes. Membranes were blocked with $5 \%$ skim milk (wt/vol) in TBS for $1 \mathrm{~h}$ at room temperature, washed several times with TBS-T ( $0.1 \%$ Tween-20 in PBS), and incubated overnight at $4{ }^{\circ} \mathrm{C}$ in blocking buffer containing the appropriate primary antibody. Antibodies and dilutions were as follows: mouse monoclonal anti-NFATc1 (1/1,000; Enzo Life Sciences), mouse monoclonal anti-NFATc2 (1/1,000; Abcam), rabbit polyclonal anti-NFATc3 (1/1,000; Santa Cruz Biotechnology, Inc.), rabbit polyclonal anti-NFATc4 (1/1,000; Santa Cruz Biotechnology, Inc.), rabbit polyclonal anti-RCAN1 serum
$(1 / 500$ in TBS-T; Porta et al., 2007), mouse monoclonal anti- $\alpha$-tubulin (1/40,000; Sigma-Aldrich), and mouse IgG1 polypyrimidine tract-binding protein-associated splicing factor (PSF; 1/1,000; Sigma-Aldrich). After $3 \times 5 \mathrm{~min}$ washes in TBS-T, blots were incubated for $1 \mathrm{~h}$ at room temperature with peroxidase-labeled goat anti-mouse or anti-rabbit IgG (Thermo Fisher Scientific; 1/5,000 in blocking solution). After $3 \times 5$ min washes in TBS-T and one in water, membrane-bound antibody was detected with enhanced chemiluminescence (ECL) detection reagent (Millipore).

RT and real-time PCR analysis. $2 \mu \mathrm{g}$ of total RNA was reverse transcribed at $37^{\circ} \mathrm{C}$ for $50 \mathrm{~min}$ in a $20-\mu \mathrm{l}$ reaction mix containing $200 \mathrm{U}$ Moloney murine leukemia virus (MMLV) RT (Invitrogen), $100 \mathrm{ng}$ of random primers, and $40 \mathrm{U}$ RNase Inhibitor (Invitrogen). Reactions were terminated by heating to $95^{\circ} \mathrm{C}$ for $5 \mathrm{~min}$, and samples were stored at $-70^{\circ} \mathrm{C}$. The following PCR primers and TaqMan probes were purchased from Applied Biosystems and optimized according to the manufacturer's protocol: 18S, rat Rcan1 (Rn00596606_m1), mouse Rcan1 (Mm00627762_m1), mouse Tbp (Mm00446973_m1), and mouse Hprt1 (Mm00446968_m1). Reactions were incubated in the presence of AmpliTaq Gold DNA polymerase (Applied Biosystems) for $2 \mathrm{~min}$ at $50^{\circ} \mathrm{C}$ followed by $10 \mathrm{~min}$ at $95^{\circ} \mathrm{C}$. Reactions were then run over 40 cycles of $95^{\circ} \mathrm{C}$ for $15 \mathrm{~s}$ and $60^{\circ} \mathrm{C}$ for $1 \mathrm{~min}$. $18 \mathrm{~S}$ rRNA transcripts were detected as an internal control gene for rat samples, whereas Tbp or Hprt 1 were used for mouse samples. Internal controls were amplified in the same tube to normalize for variation in input RNA. The amount of target mRNA in samples was estimated by the 2CT relative quantification method. Ratios were calculated between the amounts of mRNA from stimulated and nonstimulated control VSMCs.

Agilent gene expression array assay. Total RNA was isolated from VSMCs stimulated with saline, AngII, CsA, or CsA plus AngII. Total RNA $(n=4)$ was processed, and Cy3-labeled cRNA was prepared and hybridized for expression analysis to mouse G4122F $4 \times 44 \mathrm{~K}$ Whole Genome arrays (Agilent Technologies). Arrays were scanned and analyzed using Feature Extraction software v9.5.3.1 (Agilent Technologies) and preprocessed with GeneSpring v10 (Agilent Technologies). Raw signal values were thresholded to 1 and arrays were normalized using quantiles (Bolstad et al., 2003). Probes with normalized signal values greater than the 20th lower percentile were retained if flagged as present or marginal in $75 \%$ of the replicates in two of the four conditions. Finally, one-way ANOVA was used to identify probes that change in at least one condition $(\mathrm{P}<0.05)$, and these probes were retained. 1868 probes were used for differential gene expression analysis, which was performed with the limma package from Bioconductor (Smyth, 2004). Raw gene expression data are available at http://www.ncbi .nlm.nih.gov/projects/geo/ under accession no. GSE31321.

CN phosphatase activity. CN enzyme activity in aortic tissues and VSMC extracts was analyzed with the Biomol Green Calcineurin Assay kit (Enzo Life Sciences) according to the manufacturer's instructions.

Statistical analysis. All values are expressed as means \pm SEM. Differences were evaluated using one-way ANOVA and Bonferroni's post-hoc test (experiments with three or more groups). Statistical significance was assigned at $\mathrm{P}<0.05$.

Online supplemental material. Fig. S1 shows that AngII induces a sustained activation of the CN-NFAT pathway in VSMCs in vivo. Fig. S2 shows infection efficiency of VSMCs with lentiviruses expressing GFP fused to LxVP, LxVPmut, and VIVIT peptides and illustrates that VIVIT and LxVP peptides inhibit AngII-induced VSMC migration. Fig. S3 shows that AngII induces Rcan1-4 gene expression and Rcan1-4 promoter activation in rat VSMCs. Fig. $\mathrm{S} 4$ shows that Rcan1 gene targeting does not alter $\mathrm{CN}$ activity in VSMCs or aortic tissues. Fig. S5 shows that adenoviral infection drives ectopic expression of Rcan1-4 in Rcan1 ${ }^{-/-}$VSMCs in vitro. Fig. S6 illustrates Rcan1 and CD3 expression in sections from injured femoral artery. Fig. S7 shows the expression of Rcan1 in SMA-positive cells of aneurysmal sections. Online supplemental material is available at http://www .jem.org/cgi/content/full/jem.20110503/DC1. 
We thank Dr. T. Minami for providing RCAN1-4 luciferase reporters and adenovirus; Dr. Ginés Sanz for help and continuous support; Drs. S. de la Luna, S. Lamas, A. Alfranca, M. Zeini, and B. Ibáñez for critical reading of the manuscript; Dr. S. Bartlett for excellent English editorial work; and L. Iturri for technical support. We also thank the CNIC's Genomics Unit for technical support with gene expression array assays. M.R. Campanero is supported by the Spanish Council for Scientific Research (CSIC) and the Spanish Ministry of Science and Innovation (Ministerio de Ciencia e Innovación; SAF2007-60647 and SAF2010-15126); J.M. Redondo is supported by the Spanish Ministry of Science and Innovation (Ministerio de Ciencia e Innovación; SAF2009-10708), the Comunidad de Madrid (CAM-S2006/BI0-0194), Fundación La Marató TV3 (080731), and Fundación Genoma España (GENOMA). The Red Temática de Investigación Cooperativa en Enfermedades Cardiovasculares (RECAVA) of the Spanish Ministry of Health (Ministerio de Sanidad y Consumo) supports the research of J.M. Redondo, M. Salaices, and L. Vila with grants RD06/0014/0005, RD06/0014/0011 and RD06/0014/1005, respectively. Red HERACLES (RD06/0009/0008) supports the research of M. Roqué. The Centro Nacional de Investigaciones Cardiovasculares (CNIC) is supported by the Spanish Ministry of Science and Innovation and the Pro-CNIC Foundation. V. Esteban is an investigator of the Sara Borrell Program (CD06/00232) program, and N. Méndez-Barbero holds an FPU fellowship (FPU2008-1500).

The authors have no conflicting financial interests.

\section{Submitted: 10 March 2011}

Accepted: 22 August 2011

\section{REFERENCES}

Abbasi, S., J.D. Lee, B. Su, X. Chen, J.L. Alcon, J. Yang, R.E. Kellems, and Y. Xia. 2006. Protein kinase-mediated regulation of calcineurin through the phosphorylation of modulatory calcineurin-interacting protein 1. J. Biol. Chem. 281:7717-7726. http://dx.doi.org/10.1074/jbc M510775200

Aramburu, J., M.B. Yaffe, C. López-Rodríguez, L.C. Cantley, P.G. Hogan, and A. Rao. 1999. Affinity-driven peptide selection of an NFAT inhibitor more selective than cyclosporin A. Science. 285:2129-2133. http:// dx.doi.org/10.1126/science.285.5436.2129

Baek, K.H., A. Zaslavsky, R.C. Lynch, C. Britt, Y. Okada, R.J. Siarey, M.W. Lensch, I.H. Park, S.S. Yoon, T. Minami, et al. 2009. Down's syndrome suppression of tumour growth and the role of the calcineurin inhibitor DSCR1. Nature. 459:1126-1130. http://dx.doi.org/ 10.1038 /nature 08062

Benigni, A., P. Cassis, and G. Remuzzi. 2010. Angiotensin II revisited: new roles in inflammation, immunology and aging. EMBO Mol Med. 2:247257. http://dx.doi.org/10.1002/emmm.201000080

Berk, B.C. 2001. Vascular smooth muscle growth: autocrine growth mechanisms. Physiol. Rev. 81:999-1030.

Berk, B.C., V. Vekshtein, H.M. Gordon, and T. Tsuda. 1989. Angiotensin II-stimulated protein synthesis in cultured vascular smooth muscle cells. Hypertension. 13:305-314.

Bhatia, V., R. Bhatia, and M. Dhindsa. 2004. Drug-eluting stents: new era and new concerns. Postgrad. Med. J. 80:13-18. http://dx.doi.org/10.1136/ pmj.2003.009431

Bolstad, B.M., R.A. Irizarry, M. Astrand, and T.P. Speed. 2003. A comparison of normalization methods for high density oligonucleotide array data based on variance and bias. Bioinformatics. 19:185-193. http://dx.doi.org/10 .1093/bioinformatics/19.2.185

Cano, E., A. Canellada, T. Minami, T. Iglesias, and J.M. Redondo. 2005. Depolarization of neural cells induces transcription of the Down syndrome critical region 1 isoform 4 via a calcineurin/nuclear factor of activated T cells-dependent pathway. J. Biol. Chem. 280:29435-29443. http://dx.doi.org/10.1074/jbc.M506205200

Cardenas, M.E., R.S. Muir, T. Breuder, and J. Heitman. 1995. Targets of immunophilin-immunosuppressant complexes are distinct highly conserved regions of calcineurin A. EMBO J. 14:2772-2783.

Casscells, W. 1992. Migration of smooth muscle and endothelial cells. Critical events in restenosis. Circulation. 86:723-729.

Chaikof, E.L., D.C. Brewster, R.L. Dalman, M.S. Makaroun, K.A. Illig, G.A. Sicard, C.H. Timaran, G.R. Upchurch Jr., and F.J. Veith. 2009. SVS practice guidelines for the care of patients with an abdominal aortic aneurysm:
executivesummary.J.Vasc. Surg. 50:880-896.http://dx.doi.org/10.1016/ j.jvs.2009.07.001

Cho, Y.J., M. Abe, S.Y. Kim, and Y. Sato. 2005. Raf-1 is a binding partner of DSCR1. Arch. Biochem. Biophys. 439:121-128. http://dx.doi .org/10.1016/j.abb.2005.05.002

Crabtree, G.R., and E.N. Olson. 2002. NFAT signaling: choreographing the social lives of cells. Cell. 109:S67-S79. http://dx.doi.org/10.1016/ S0092-8674(02)00699-2

Curci, J.A. 2009. Digging in the "soil" of the aorta to understand the growth of abdominal aortic aneurysms. Vascular. 17:S21-S29. http://dx.doi.org/10 $.2310 / 6670.2008 .00085$

Daugherty, A., and L.A. Cassis. 2004. Mouse models of abdominal aortic aneurysms. Arterioscler. Thromb. Vasc. Biol. 24:429-434. http://dx.doi.org/10 .1161/01.ATV.0000118013.72016.ea

Daugherty, A., M.W. Manning, and L.A. Cassis. 2000. Angiotensin II promotes atherosclerotic lesions and aneurysms in apolipoprotein E-deficient mice. J. Clin. Invest. 105:1605-1612. http://dx.doi.org/10.1172/JCI7818

Davies, K.J., G. Ermak, B.A. Rothermel, M. Pritchard, J. Heitman, J. Ahnn, F. Henrique-Silva, D. Crawford, S. Canaider, P. Strippoli, et al. 2007. Renaming the DSCR1/Adapt78 gene family as RCAN: regulators of calcineurin. FASEB J. 21:3023-3028. http://dx.doi.org/10.1096/ fj. $06-7246 \mathrm{com}$

Eichler, G.S., S. Huang, and D.E. Ingber. 2003. Gene Expression Dynamics Inspector (GEDI): for integrative analysis of expression profiles. Bioinformatics. 19:2321-2322. http://dx.doi.org/10.1093/ bioinformatics/btg307

Emori, T., Y. Hirata, K. Ohta, M. Shichiri, and F. Marumo. 1989. Secretory mechanism of immunoreactive endothelin in cultured bovine endothelial cells. Biochem. Biophys. Res. Commun. 160:93-100. http://dx.doi.org/ 10.1016/0006-291X(89)91625-2

Esteban, V., O. Lorenzo, M. Rupérez, Y. Suzuki, S. Mezzano, J. Blanco, M. Kretzler, T. Sugaya, J. Egido, and M. Ruiz-Ortega. 2004 Angiotensin II, via AT1 and AT2 receptors and NF-kappaB pathway, regulates the inflammatory response in unilateral ureteral obstruction. J. Am. Soc. Nephrol. 15:1514-1529. http://dx.doi.org/10.1097/01 .ASN.0000130564.75008.F5

Forte, A., A. Della Corte, M. De Feo, F. Cerasuolo, and M. Cipollaro. 2010. Role of myofibroblasts in vascular remodelling: focus on restenosis and aneurysm. Cardiovasc. Res. 88:395-405. http://dx.doi.org/10.1093/ $\mathrm{cvr} / \mathrm{cvq} 224$

Fuentes, J.J., M.A. Pritchard, and X. Estivill. 1997. Genomic organization, alternative splicing, and expression patterns of the DSCR1 (Down syndrome candidate region 1) gene. Genomics. 44:358-361. http://dx.doi.org/10 $.1006 /$ geno.1997.4866

Gavrila, D., W.G. Li, M.L. McCormick, M.Thomas, A. Daugherty, L.A. Cassis, FJ. Miller Jr., L.W. Oberley, K.C. Dellsperger, and N.L. Weintraub. 2005.Vitamin $\mathrm{E}$ inhibits abdominal aortic aneurysm formation in angiotensin II-infused apolipoprotein E-deficient mice. Arterioscler. Thromb. Vasc. Biol. 25:1671-1677. http://dx.doi.org/10.1161/01.ATV.0000172631.50972.0f

Geisterfer, A.A., M.J. Peach, and G.K. Owens. 1988. Angiotensin II induces hypertrophy, not hyperplasia, of cultured rat aortic smooth muscle cells. Circ. Res. 62:749-756.

Genescà, L., A. Aubareda, J.J. Fuentes, X. Estivill, S. De La Luna, and M. Pérez-Riba. 2003. Phosphorylation of calcipressin 1 increases its ability to inhibit calcineurin and decreases calcipressin half-life. Biochem. J. 374:567-575. http://dx.doi.org/10.1042/BJ20030267

Goetze, S., X.P. Xi, H. Kawano, T. Gotlibowski, E. Fleck, W.A. Hsueh, and R.E. Law. 1999. PPAR gamma-ligands inhibit migration mediated by multiple chemoattractants in vascular smooth muscle cells. J. Cardiovasc. Pharmacol. 33:798-806. http://dx.doi.org/10.1097/ 00005344-199905000-00018

Graef, I.A., F. Chen, L. Chen, A. Kuo, and G.R. Crabtree. 2001. Signals transduced by $\mathrm{Ca}(2+) /$ calcineurin and NFATc3/c4 pattern the developing vasculature. Cell. 105:863-875. http://dx.doi.org/10.1016/ S0092-8674(01)00396-8

Graef, I.A., F. Wang, F. Charron, L. Chen, J. Neilson, M. Tessier-Lavigne, and G.R. Crabtree. 2003. Neurotrophins and netrins require calcineurin/NFAT signaling to stimulate outgrowth of embryonic axons. Cell. 113:657-670. http://dx.doi.org/10.1016/S0092-8674(03)00390-8 
Greene, E.L., G. Lu, D. Zhang, and B.M. Egan. 2001. Signaling events mediating the additive effects of oleic acid and angiotensin II on vascular smooth muscle cell migration. Hypertension. 37:308-312.

Guo, J., H. Chen, J. Ho, J. Mancini, T. Sontag, S.A. Laporte, D.E. Richard, and J.J. Lebrun. 2009. TGFbeta-induced GRK2 expression attenuates AngII-regulated vascular smooth muscle cell proliferation and migration. Cell. Signal. 21:899-905. http://dx.doi.org/10.1016/ j.cellsig.2009.01.037

Heeneman, S., J.C. Sluimer, and M.J. Daemen. 2007. Angiotensin-converting enzyme and vascular remodeling. Circ. Res. 101:441-454. http://dx.doi .org/10.1161/CIRCRESAHA.107.148338

Heit, J.J., A.A. Apelqvist, X. Gu, M.M. Winslow, J.R. Neilson, G.R. Crabtree, and S.K. Kim. 2006. Calcineurin/NFAT signalling regulates pancreatic beta-cell growth and function. Nature. 443:345-349. http:// dx.doi.org/10.1038/nature 05097

Hoeffer, C.A., A. Dey, N. Sachan, H. Wong, R.J. Patterson, J.M. Shelton, J.A. Richardson, E. Klann, and B.A. Rothermel. 2007. The Down syndrome critical region protein RCAN1 regulates long-term potentiation and memory via inhibition of phosphatase signaling. J. Neurosci. 27:1316113172. http://dx.doi.org/10.1523/JNEUROSCI.3974-07.2007

Hogan, P.G., L. Chen, J. Nardone, and A. Rao. 2003. Transcriptional regulation by calcium, calcineurin, and NFAT. Genes Dev. 17:2205-2232. http://dx.doi.org/10.1101/gad.1102703

Iakovou, I., T. Schmidt, E. Bonizzoni, L. Ge, G.M. Sangiorgi, G. Stankovic, F. Airoldi, A. Chieffo, M. Montorfano, M. Carlino, et al. 2005. Incidence, predictors, and outcome of thrombosis after successful implantation of drug-eluting stents. JAMA. 293:2126-2130. http://dx.doi .org/10.1001/jama.293.17.2126

Jain, J., Z. Miner, and A. Rao. 1993. Analysis of the preexisting and nuclear forms of nuclear factor of activated T cells. J. Immunol. 151:837-848.

Kiani, A., A. Rao, and J. Aramburu. 2000. Manipulating immune responses with immunosuppressive agents that target NFAT. Immunity. 12:359372. http://dx.doi.org/10.1016/S1074-7613(00)80188-0

Kingsbury, T.J., and K.W. Cunningham. 2000. A conserved family of calcineurin regulators. Genes Dev. 14:1595-1604.

Lee, E.J., S.R. Seo, J.W. Um, J. Park, Y. Oh, and K.C. Chung. 2008. NFkappaB-inducing kinase phosphorylates and blocks the degradation of Down syndrome candidate region 1. J. Biol. Chem. 283:3392-3400. http://dx.doi.org/10.1074/jbc.M706707200

Li, F., C. Zhang, S. Schaefer, A. Estes, and K.U. Malik. 2005. ANG II-induced neointimal growth is mediated via cPLA2- and PLD2activated Akt in balloon-injured rat carotid artery. Am. J. Physiol. Heart Circ. Physiol. 289:H2592-H2601. http://dx.doi.org/10.1152/ ajpheart.00450.2005

Liu, J., J.D. Farmer Jr., W.S. Lane, J. Friedman, I. Weissman, and S.L. Schreiber. 1991. Calcineurin is a common target of cyclophilin-cyclosporin A and FKBP-FK506 complexes. Cell. 66:807-815. http://dx.doi.org/10 $.1016 / 0092-8674(91) 90124-\mathrm{H}$

Liu, J., E.S. Masuda, L. Tsuruta, N. Arai, and K. Arai. 1999. Two independent calcineurin-binding regions in the $\mathrm{N}$-terminal domain of murine NF-ATx1 recruit calcineurin to murine NF-ATx1. J. Immunol. 162:4755-4761.

Liu, Q., J.C. Busby, and J.D. Molkentin. 2009. Interaction between TAK1-TAB1-TAB2 and RCAN1-calcineurin defines a signalling nodal control point. Nat. Cell Biol. 11:154-161. http://dx.doi .org $/ 10.1038 /$ ncb1823

Liu, Z., C. Zhang, N. Dronadula, Q. Li, and G.N. Rao. 2005. Blockade of nuclear factor of activated $\mathrm{T}$ cells activation signaling suppresses balloon injury-induced neointima formation in a rat carotid artery model. J. Biol. Chem. 280:14700-14708. http://dx.doi.org/10.1074/ jbc.M500322200

Maiellaro, K., and W.R. Taylor. 2007. The role of the adventitia in vascular inflammation. Cardiovasc. Res. 75:640-648. http://dx.doi.org/10.1016/ j.cardiores.2007.06.023

Martin-McNulty, B., J. Vincelette, R. Vergona, M.E. Sullivan, and Y.X. Wang. 2005. Noninvasive measurement of abdominal aortic aneurysms in intact mice by a high-frequency ultrasound imaging system. Ultrasound Med. Biol. 31:745-749. http://dx.doi.org/10.1016/ j.ultrasmedbio.2005.02.012
Martínez-Martínez, S., and J.M. Redondo. 2004. Inhibitors of the calcineurin/NFAT pathway. Curr. Med. Chem. 11:997-1007. http://dx.doi .org/10.2174/0929867043455576

Martínez-Martínez, S., A. Rodríguez, M.D. López-Maderuelo, I. OrtegaPérez, J. Vázquez, and J.M. Redondo. 2006. Blockade of NFAT activation by the second calcineurin binding site. J. Biol. Chem. 281:6227-6235. http://dx.doi.org/10.1074/jbc.M513885200

Marx, S.O., and A.R. Marks. 2001. Bench to bedside: the development of rapamycin and its application to stent restenosis. Circulation. 104: $852-855$.

Minami, T., K. Horiuchi, M. Miura, M.R. Abid, W. Takabe, N. Noguchi, T. Kohro, X. Ge, H. Aburatani, T. Hamakubo, et al. 2004. Vascular endothelial growth factor- and thrombin-induced termination factor, Down syndrome critical region-1, attenuates endothelial cell proliferation and angiogenesis. J. Biol. Chem. 279:50537-50554. http://dx.doi.org/10.1074/ jbc.M406454200

Minami, T., K. Yano, M. Miura, M. Kobayashi, J. Suehiro, P.C. Reid, T. Hamakubo, S. Ryeom, W.C. Aird, and T. Kodama. 2009. The Down syndrome critical region gene 1 short variant promoters direct vascular bed-specific gene expression during inflammation in mice. J. Clin. Invest. 119:2257-2270.

Molkentin, J.D., J.R. Lu, C.L. Antos, B. Markham, J. Richardson, J. Robbins, S.R. Grant, and E.N. Olson. 1998. A calcineurin-dependent transcriptional pathway for cardiac hypertrophy. Cell. 93:215-228. http://dx.doi.org/10.1016/S0092-8674(00)81573-1

Naftilan, A.J., R.E. Pratt, and V.J. Dzau. 1989. Induction of platelet-derived growth factor A-chain and c-myc gene expressions by angiotensin II in cultured rat vascular smooth muscle cells. J. Clin. Invest. 83:1419-1424. http://dx.doi.org/10.1172/JCI114032

Nagata, D., R. Takeda, M. Sata, H. Satonaka, E. Suzuki, T. Nagano, and Y. Hirata. 2004. AMP-activated protein kinase inhibits angiotensin IIstimulated vascular smooth muscle cell proliferation. Circulation. 110:444451. http://dx.doi.org/10.1161/01.CIR.0000136025.96811.76

Owens, G.K. 1989. Control of hypertrophic versus hyperplastic growth of vascular smooth muscle cells. Am. J. Physiol. 257:H1755-H1765.

Owens, G.K. 1995. Regulation of differentiation of vascular smooth muscle cells. Physiol. Rev. 75:487-517.

Porta, S., S.A. Serra, M. Huch, M.A. Valverde, F. Llorens, X. Estivill, M.L. Arbonés, and E. Martí. 2007. RCAN1 (DSCR1) increases neuronal susceptibility to oxidative stress: a potential pathogenic process in neurodegeneration. Hum. Mol. Genet. 16:1039-1050. http://dx.doi.org/10 $.1093 / \mathrm{hmg} / \mathrm{ddm} 049$

Rodríguez, A., J. Roy, S. Martínez-Martínez, M.D. López-Maderuelo, P. Niño-Moreno, L. Ortí, D. Pantoja-Uceda, A. Pineda-Lucena, M.S. Cyert, and J.M. Redondo. 2009. A conserved docking surface on calcineurin mediates interaction with substrates and immunosuppressants. Mol. Cell. 33:616-626. http://dx.doi.org/10.1016/ j.molcel.2009.01.030

Roque, M., J.T. Fallon, J.J. Badimon, W.X. Zhang, M.B. Taubman, and E.D. Reis. 2000. Mouse model of femoral artery denudation injury associated with the rapid accumulation of adhesion molecules on the luminal surface and recruitment of neutrophils. Arterioscler. Thromb. Vasc. Biol. 20:335-342. http://dx.doi.org/10.1161/01.ATV.20.2.335

Rothermel, B., R.B. Vega, J. Yang, H. Wu, R. Bassel-Duby, and R.S. Williams. 2000. A protein encoded within the Down syndrome critical region is enriched in striated muscles and inhibits calcineurin signaling. J. Biol. Chem. 275:8719-8725. http://dx.doi.org/10.1074/jbc .275 .12 .8719

Rothermel, B.A., T.A. McKinsey, R.B. Vega, R.L. Nicol, P. Mammen, J. Yang, C.L. Antos, J.M. Shelton, R. Bassel-Duby, E.N. Olson, and R.S. Williams. 2001. Myocyte-enriched calcineurin-interacting protein, MCIP1, inhibits cardiac hypertrophy in vivo. Proc. Natl. Acad. Sci. USA. 98:3328-3333. http://dx.doi.org/10.1073/pnas.041614798

Ryeom, S., R.J. Greenwald, A.H. Sharpe, and F. McKeon. 2003. The threshold pattern of calcineurin-dependent gene expression is altered by loss of the endogenous inhibitor calcipressin. Nat. Immunol. 4:874-881. http://dx.doi.org/10.1038/ni966

Ryeom, S., K.H. Baek, M.J. Rioth, R.C. Lynch, A. Zaslavsky, A. Birsner, S.S. Yoon, and F. McKeon. 2008. Targeted deletion of the calcineurin 
inhibitor DSCR1 suppresses tumor growth. Cancer Cell. 13:420-431. http://dx.doi.org/10.1016/j.ccr.2008.02.018

Sakalihasan, N., R. Limet, and O.D. Defawe. 2005. Abdominal aortic aneurysm. Lancet. 365:1577-1589. http://dx.doi.org/10.1016/S01406736(05)66459-8

Sartore, S., R. Franch, M. Roelofs, and A. Chiavegato. 1999. Molecular and cellular phenotypes and their regulation in smooth muscle. Rev. Physiol. Biochem. Pharmacol. 134:235-320.

Sartore, S., A. Chiavegato, E. Faggin, R. Franch, M. Puato, S. Ausoni, and P. Pauletto. 2001. Contribution of adventitial fibroblasts to neointima formation and vascular remodeling: from innocent bystander to active participant. Circ. Res. 89:1111-1121. http://dx.doi.org/10.1161/hh2401 .100844

Satoh, K., P. Nigro, T. Matoba, M.R. O’Dell, Z. Cui, X. Shi, A. Mohan, C. Yan, J. Abe, K.A. Illig, and B.C. Berk. 2009. Cyclophilin A enhances vascular oxidative stress and the development of angiotensin II-induced aortic aneurysms. Nat. Med. 15:649-656. http://dx.doi.org/10.1038/ nm.1958

Satonaka, H., E. Suzuki, H. Nishimatsu, S. Oba, R. Takeda, A. Goto, M. Omata, T. Fujita, R. Nagai, and Y. Hirata. 2004. Calcineurin promotes the expression of monocyte chemoattractant protein-1 in vascular myocytes and mediates vascular inflammation. Circ. Res. 94:693-700. http://dx.doi.org/10.1161/01.RES.0000118250.67032.5E

Sayeski, P.P., and M.S. Ali. 2003. The critical role of c-Src and the Shc/ Grb2/ERK2 signaling pathway in angiotensin II-dependent VSMC proliferation. Exp. Cell Res. 287:339-349. http://dx.doi.org/10.1016/ S0014-4827(03)00154-X

Schwartz, S.M. 1997. Perspectives series: cell adhesion in vascular biology Smooth muscle migration in atherosclerosis and restenosis. J. Clin. Invest. 99:2814-2816. http://dx.doi.org/10.1172/JCI119472

Schwartz, S.M., D. deBlois, and E.R. O'Brien. 1995. The intima. Soil for atherosclerosis and restenosis. Circ. Res. 77:445-465.

Scott-Burden, T., T.J. Resink, A.W. Hahn, and P.M. Vanhoutte. 1991 Induction of endothelin secretion by angiotensin II: effects on growth and synthetic activity of vascular smooth muscle cells. J. Cardiovasc. Pharmacol. 17:S96-S100. http://dx.doi.org/10.1097/00005344199100177-00025

Shin, S.Y., H.W. Yang, J.R. Kim, W. Do Heo, and K.H. Cho. 2011 A hidden incoherent switch regulates RCAN1 in the calcineurin-NFAT signaling network. J. Cell Sci. 124:82-90. http://dx.doi.org/10.1242/ jcs.076034
Smyth, G.K. 2004. Linear models and empirical bayes methods for assessing differential expression in microarray experiments. Stat. Appl. Genet. Mol. Biol. 3:e3

Suzuki, E., H. Nishimatsu, H. Satonaka, K. Walsh, A. Goto, M. Omata, T. Fujita, R. Nagai, and Y. Hirata. 2002. Angiotensin II induces myocyte enhancer factor 2- and calcineurin/nuclear factor of activated $\mathrm{T}$ celldependent transcriptional activation in vascular myocytes. Circ. Res. 90: 1004-1011. http://dx.doi.org/10.1161/01.RES.0000017629.70769.CC

Touyz, R.M. 2005. Intracellular mechanisms involved in vascular remodelling of resistance arteries in hypertension: role of angiotensin II. Exp. Physiol. 90:449-455. http://dx.doi.org/10.1113/expphysiol.2005.030080

van Kleef, E.M., J. Fingerle, and M.J. Daemen. 1996. Angiotensin IIinduced progression of neointimal thickening in the balloon-injured rat carotid artery is AT1 receptor mediated. Arterioscler. Thromb. Vasc. Biol. 16:857-863. http://dx.doi.org/10.1161/01.ATV.16.7.857

Vega, R.B., B.A. Rothermel, C.J. Weinheimer, A. Kovacs, R.H. Naseem, R. Bassel-Duby, R.S. Williams, and E.N. Olson. 2003. Dual roles of modulatory calcineurin-interacting protein 1 in cardiac hypertrophy. Proc. Natl. Acad. Sci. USA. 100:669-674. http://dx.doi.org/10.1073/pnas.0237225100

Waseda, K., A. Miyazawa, J. Ako, T. Hasegawa, I. Tsujino, R. Sakurai, P.G. Yock, Y. Honda, D.E. Kandzari, M.B. Leon, and P.J. Fitzgerald; ENDEAVOR IV Trial Investigators. 2009. Intravascular ultrasound results from the ENDEAVOR IV trial: randomized comparison between zotarolimus- and paclitaxel-eluting stents in patients with coronary artery disease. JACC Cardiovasc. Interv. 2:779-784.http://dx.doi .org/10.1016/j.jcin.2009.05.015

Watanabe, T., R. Pakala, T. Katagiri, and C.R. Benedict. 2001. Serotonin potentiates angiotensin II-induced vascular smooth muscle cell proliferation. Atherosclerosis. 159:269-279. http://dx.doi.org/10.1016/S00219150(01)00505-6

Weintraub, N.L. 2009. Understanding abdominal aortic aneurysm. N. Engl. J. Med. 361:1114-1116. http://dx.doi.org/10.1056/NEJMcibr0905244

Yang, Y.J., W. Chen, A. Edgar, B. Li, J.D. Molkentin, J.N. Berman, and T.J. Lin. 2009. Rcan1 negatively regulates Fc epsilonRI-mediated signaling and mast cell function. J. Exp. Med. 206:195-207. http://dx.doi .org/10.1084/jem.20081140

Yellaturu, C.R., S.K. Ghosh, R.K. Rao, L.K. Jennings, A. Hassid, and G.N. Rao. 2002. A potential role for nuclear factor of activated $\mathrm{T}$-cells in receptor tyrosine kinase and G-protein-coupled receptor agonist-induced cell proliferation. Biochem. J. 368:183-190. http://dx.doi .org/10.1042/BJ20020347 